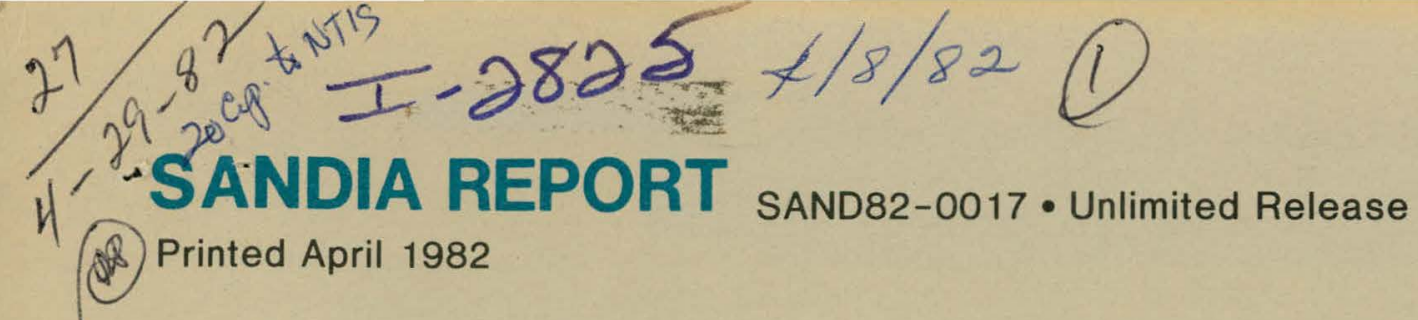

\title{
MASTER
}

\section{A Review of Subsidence Prediction Research Conducted at Sandia National Laboratories}

Herbert J. Sutherland, Karl W. Schuler

\section{Prepared by}

Sandia National Laboratories

Albuquerque, New Mexico 87185 and Livermore, California 94550

for the United States Department of Energy

under Contract DE-AC04-76DP00789

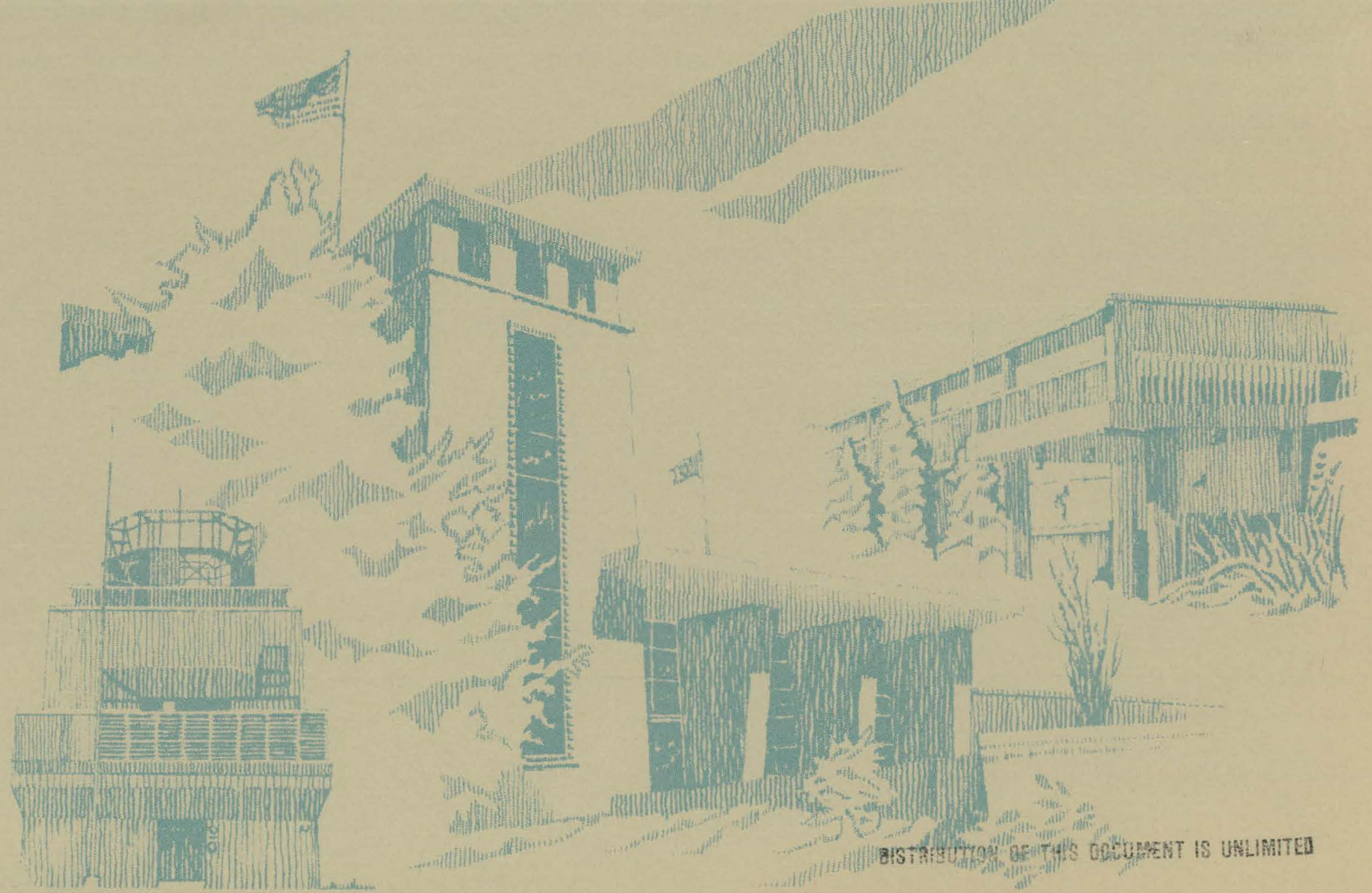




\section{DISCLAIMER}

This report was prepared as an account of work sponsored by an agency of the United States Government. Neither the United States Government nor any agency Thereof, nor any of their employees, makes any warranty, express or implied, or assumes any legal liability or responsibility for the accuracy, completeness, or usefulness of any information, apparatus, product, or process disclosed, or represents that its use would not infringe privately owned rights. Reference herein to any specific commercial product, process, or service by trade name, trademark, manufacturer, or otherwise does not necessarily constitute or imply its endorsement, recommendation, or favoring by the United States Government or any agency thereof. The views and opinions of authors expressed herein do not necessarily state or reflect those of the United States Government or any agency thereof. 


\section{DISCLAIMER}

Portions of this document may be illegible in electronic image products. Images are produced from the best available original document. 
Issued by Sandia National Laboratories, operated for the United States Department of Energy by Sandia Corporation.

NOTICE: This report was prepared as an account of work sponsored by an agency of the United States Government. Neither the United States Government nor any agency thereof, nor any of their employees, nor any of their ment nor any agency thereof, nor any of their employees, nor any of their contractors, subcontractors, or their employees, makes any warranty, express completeness, or usefulness of any information, apparatus, product, or process disclosed, or represents that its use would not infringe privately owned rights. Reference herein to any specific commercial product, process, service by trade name, trademark, manufacturer, or otherwise, does not necessarily constitute or imply its endorsement, recommendation, or favoring by the United States Government, any agency thereof or any of thei contractors or subcontractors. The views and opinions expressed herein do not necessarily state or reflect those of the United States Government, any agency thereof or any of their contractors or subcontractors.

Printed in the United States of America Available from

National Technical Information Service U.S. Department of Commerce

5285 Port Royal Road

Springfield, VA 22161

NTIS price codes

Printed copy: A03

Printed copy: A03 01 
SAND82-0017

Unlimited Distribution

SAND - -82-0017

Printed April 1982

DE82 013632

A REVIEW OF SUBSIDENCE PREDICTION RESEARCH CONDUCTED AT SANDIA NATIONAL LABORATORIES

H. J. Sutherland and K. W. Schuler Sandia National Laboratories Albuquerque, NM 87185

\begin{abstract}
This paper reviews the results of the subsidence research program at Sandia National Laboratories. The manuscript highlights the following: the application of empirical methods (profile functions) to the subsidence above longwall panels in the U.S.; the use of the "rubble model" to describe the behavior of broken strata as it distends when it falls to the mine floor (or top of the rubble pile) and then is subsequently compacted as it is loaded by. overlying elements of strata; and, the application of physical modeling techniques (centrifuge simulations) and numerical techniques to study the failure mechanisms in highly structured stratigraphy. The capabilities of the latter two are illustrated by comparing their predictions to the results of a field case that has complicated stratigraphy.
\end{abstract}


The potential increase in demand for coal as an alternative energy source for oil will, in the longterm, result, in an increase in the underground mining of coal in the heavily populated Eastern and Midwestern portions of the United States (U.S.). This trend, together with a number of state and federal laws concerning subsidence and the economic advantage of high extraction methods of mining, is providing an incentive to deal with the potential problems of subsidence. Because of this incentive, research on the characterization and prediction of subsidence and ways of controlling or mitigating its consequences are in progress.

This paper reviews the results of the subsidence research program at Sandia National Laboratories. This program is being sponsored by the U. $S$. Department of Energy, Carbondale Mining Technology Center. Its objective is to develop the techniques required to predict the surface motion and subsurface strata movements above mine openings. This program is coordinated with the Los Alamos National Scientific Laboratories' program to predict the impact of these movements on surface facilities, squifers, etc. (discussed elsewhere in these proceedings). This program has been previously reviewed by Munson and Sutherland. ${ }^{1}$

We have taken a pragmatic approach to subsidence research by tacitly dividing our research into three areas: descriptive, predictive, and prescriptive modeling. Descriptive modeling describes what has happened in the past. As the data base for thise models become statistically large, they can be extrapolated to predictive models which will predict what will happen under similar circumstances. The norms established by these predictive models can then be used to guide the researcher to variations from the norm which must be analyzed on a case-by-case basis. These analyses lead to prescriptive models which prescribe what should happen under all circumstances. For subsidence, we have drawn upon the vast amount of knowledge and experience of the European mining community to develop our descriptive models. 
To date, this effort has centered on using proflle functions to describe the subsidence trough that develops above longwall panels. Currently these techniques are being generalized to influence functions so that the same techniques may be used for both room-and-pillar and longwall mine geometries. The extrapolation of these techniques to predictive models is many years away because a statistically large subsidence data set for the United States (U.S.), or even a single geographic region in the U.S., is not currently available. This lack of data is a major obstacle to the development of a prescriptive model for subsidence. We have chosen to circumvent this obstacle by using the field data that is available in coordination with physical models based on centrifuge simulation techniques. The latter permits us to identify and study key subsidence mechanisms under closely controlled conditions; and the former keeps us in actual geological and mining environments. Using both, we are developing models for the mechanisms of subsidence. To date, these models have been based on the concept of key modes of material response and can be implemented in numerical calculations. Thus, we are using European empirical techniques, physical models, and U.S. field studies to guide our efforts to develop a prescriptive model for predicting surface and subsurface motions above mine openings. This approach has the benefit that the empirical techniques can be extrapolated to predictive models for surface motion as the U.S. subsidence data base becomes statistically lárge.

In this review, the European empirical models, evaluated for the limited U.S. data set for longwall mining, are presented first. Then a framework for a prescriptive subsidence model is given. The capabilities of the model are illustrated by comparing its predictions to the well-defined mechanisms in a physical model and then comparing its predictions for the complicated geology of a field case.

EUROPEAN EMPIRICAL METHODS

For several decades, the European coal mining industry has been forced by extensive surface utilization over operating longwall mines to deal 
realistically with subsidence. This need has led to the development of several techniques that center about empirical methods and simple analytic procedures for describing the subsidence trough. The methods are the graphical empirical methods used in the United Kingdom, and the mathematical profile and influence functions used on the continent. The first step of our study was to evaluate the graphical techniques and profile functions for domestic longwall mines. The initial analyses were conducted by Munson and Eichfeld for the old Ben No. 24 Mine in Illinois ${ }^{2}$ and the York Canyon Mine in New Mexico. ${ }^{3}$ Additional analyses have been completed on the data that have been published by Adamek and Jeran, 4 Powell, 5,6 and Hardy et al. ${ }^{7}$

Background

European methods consist esseritially of the graphical methods used in the United Kingdom (UK), which are perhaps the best known here because of the extensive compilation of case histories by the National Coal Board (NCB), 8 and the mathematical fits used on the Continent which are in the form of profile ${ }^{9}$ and influence functions. ${ }^{10}$ For longwall mining, the fundamental profiles are the transverse profile which develops along the rib sides and at right angles to the direction of mining and the longitudinal profile which develops parallel to the direction of mining. Other definitions which describe the profiles are:

1) Stationary profiles which encompass the

a) transverse profiles over the rib side.

b) longitudinal profiles formed at the beginning of the panel, where unique initial and boundary conditions occur due to the failure and collapse of a free roof span, and

c) longitudinal profiles formed at the end of the panel.

2) Non-stationary profiles which encompass the

a) traveling wave profiles measured in the panel interior as the face advances; if the subsidence has no time-dependent component, this profile is identical to the stationary end profile; and 
b) development profiles that describe the subsidence motion of a surface point as a function of face position; if there is no timedependent component and the beds are transversely isotropic, this profile is identical to the traveling wave; a special form of this curve is the time-correlated development profile that described the motion of a surface point with time.

In the definition of the various non-stationary profiles, the influence of time becomes a prominent feature. Two types of time effects occur: one is a pseudo time-dependent response which arises because of the finite mine face advance rate, and the other is a true time-dependent response which is related to material constitutive response.

The UK graphical analysis technique is derived from a large collection of subsidence field data over longwall mines, ${ }^{8}$ and therefore is one of the major comparison points for our analysis. This method predominantly treats the transverse profile; however, the development curve has been characterized also.

On the Continent, a different approach emerged for characterizing subsidence. Here investigators attempted to find methematical functions which matched measured subsidence profiles. As a consequence of the approach, there have been a number of methematical forms proposed. An asymptotic profile function which reoccurs frequently is the error integral

$$
\mathrm{s} / \mathrm{s}_{\mathrm{m}}=1 / 2 \cdot\left[1-\frac{2}{\sqrt{\pi}} \int_{0}^{\left.\frac{\pi x}{\mathrm{~B}_{e}}-\xi^{2} \mathrm{~d} \xi\right]}\right.
$$

where $\xi$ is an integration variable, $s$ is the subsidence, $s_{m}$ is the maximum subsidence, $x$ is the distance, and $B$ is the effective half-range of the function (see Figure 1). This empirical form has been successfully applied to the flat coal seams with single workings of Upper silesia (Poland).ll Another profile function, of the non-asymptotic, trignometric type,

$$
\mathrm{s} / \mathrm{s}_{\mathrm{m}}=1 / 2\left[1-\frac{\dot{x}}{\bar{B}}-\frac{1}{\pi} \sin \left(\pi \frac{\mathrm{x}}{\bar{B}}\right)\right],
$$




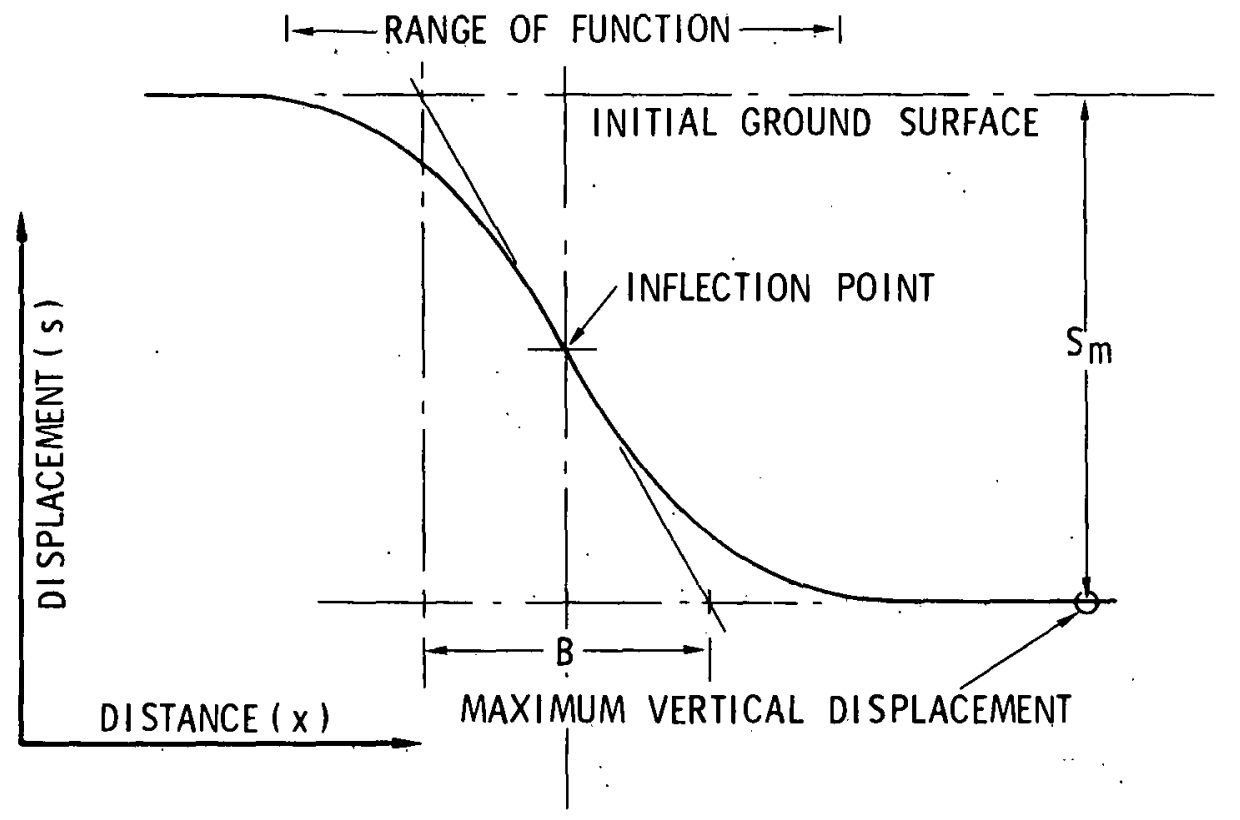

Figure 1. Schematic of the Subsidence Displacement as Described by a profile Function 
has been found to accurately match the subsidence profiles of the Donets (USSR) fields.4 In these functions, no distinction is possible between longitudinal and transverse subsidence profiles; or between traveling and boundary subsidence profiles.

\section{Case Histories}

Here, we will review the subsidence case histories for the old Ben No. 24 mine and the Shoemaker mine. These histories were chosen for review because they have important implications to the development of the predictive and prescriptive models for subsidence. In particular, the old Ben data may be used to illustrate the application of profile functions to both stationary and nonstationary profiles. Further, these data can be used to infer the magnitude of time-dependent phenomena in the subsidence process. Other case histories. from the U. S. can and have been handled in much the same manner as illustrated with this example. The Shoemaker mine was chosen because the site geology produces profiles that vary greatly from one another and, to date, are the two extremes for the U. S.

old Ben No. 24 Mine: The European empirical methods were tested first on the subsidence data from two longwall panels of the old Ben No. 24 Mine. This mine is in the Illinois Coal Basin and produces from the Illinois (Herrin) No. 6 seam. This seam is a flay lying deposit under flat terrain. A nominal $2.1 \mathrm{~m}$ thickness of coal was extracted from an approximately $2.7 \mathrm{~m}$ thick seam at a depth of $189 \mathrm{~m}:$ No previous workings existed either above or below the current mine. Panel 1 was $140 \mathrm{~m}$ wïde by $529 \mathrm{~m}$ long and Panel 2 was $140 \mathrm{~m}$ wide by $536 \mathrm{~m}$ long. Adjacent to Panel 1 was a conventional room and pillar extraction with retreat pillar robbing. A schematic of the study area is shown in Figure 2.

The relevant field measurements consisted of periodic level surveys of, three lines of surface monuments, one line transverse across both panels and one longitudinal line for each panel.12 A short base length automated system 


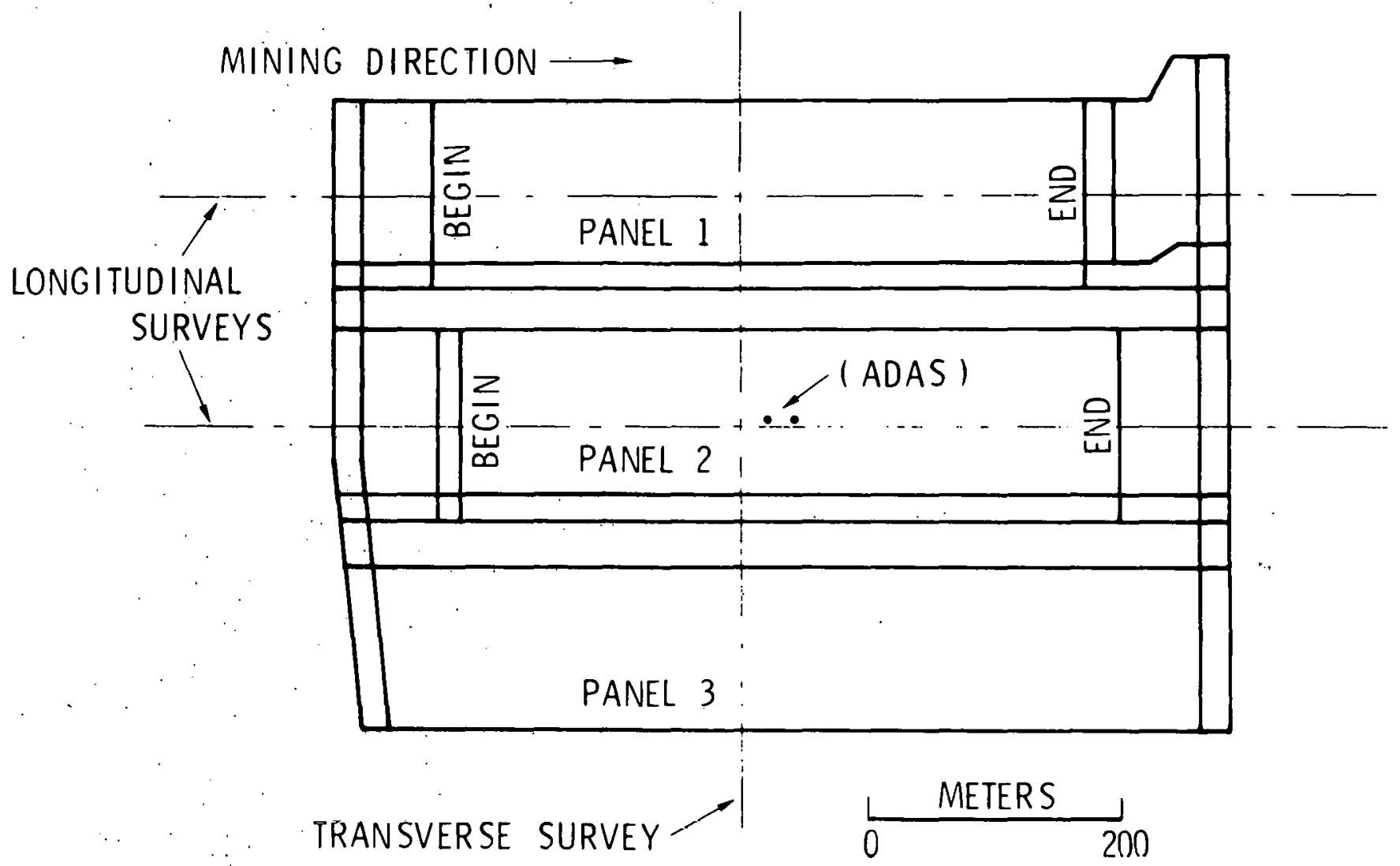

Figure 2. Panels 1 and 2 of the Old Ben No. 24 Mine and the Location of Survey Lines and the Automatic Data Acquisition System (ADAS). After Munson and Eichfeld.2 
(ADAS) was also emplaced over the interior of Panel $2^{13}$. (see Figure 2). The reported measurements give transverse stationary, longitudinal stationary, traveling wave, development, and time-correlated development profiles. Since the data from this mine are quite extensive, only representative profiles will be given here.

In Figure 3 the transverse profile for Panel 1 is given. Clearly, only the right side was treated since the ground motion on the left has been modified by previous room and pillar workings. For this subcritical situation the NCB predicts a maximum subsidence of 0.675 of the extraction height; this agrees within 158 of the observed values of about 0.59 for. Panel 1 and about 0.62 for Panel 2. However, even when normalized to the measured maximum sub sidence, the $\mathrm{NCB}$ transverse profile is a rather poor match to the field data, as shown. The UK experience suggests a profile slope much too shallow; i.e., a much larger trough than that measured. Thus, while one can obtain a reasonable measure of maximum subsidence using the UK experience, the surface strain would be considerably less than actually experienced over this Illinois mine and, in general, the profile shapes do not match.

The profile functions, Eqs. $I$ and $2 \%$ were fit to the measured transverse profile (see Figure 3). In general, the profile functions provide very good fits to the data, especially in the bottom of the trough. The measured profile has less curvature, i.e.. smaller peak strain, in the lip of the trough than the profile function. Although the reason for the greater subsidence over the solid material is not clear, this effect may be related to the true time-dependent material response or to the partial failure of the solid ribs (or pillars). Both effects could be enhanced by mine workings such as entry systems and deployment or recovery rooms. While it appears that both profile functions are adequate representations of the field results, the trignometric function is preferred because it leads to conservative predictions of the peak strain, i.e., the peak strain predicted is greater than that observed. This 


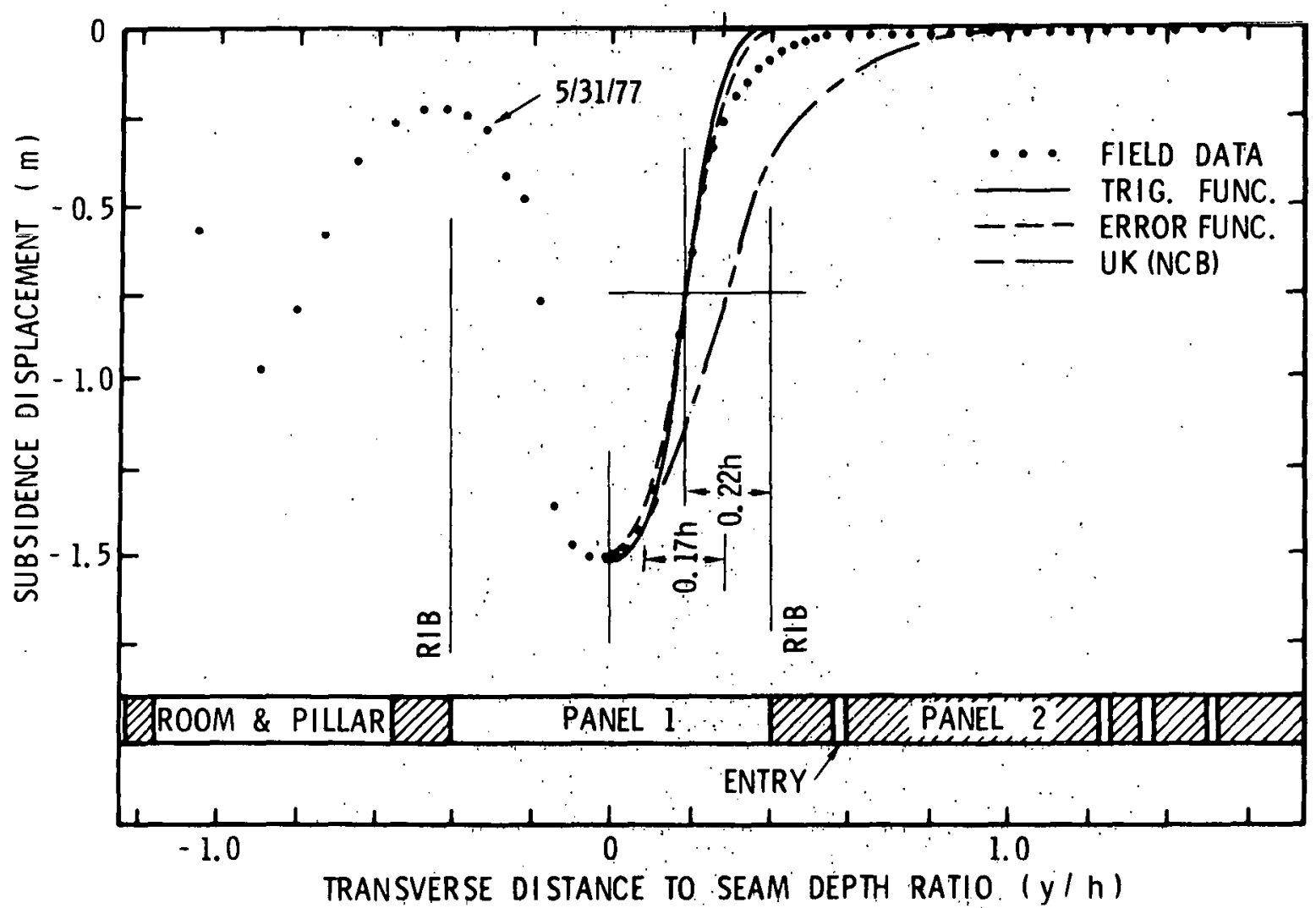

Figure 3. Comparison of the Measured Transverse Profile from old Ben Panel I and the Empirical REsults. After Munson and Eichfeld, 2 
is illustrated also in the comparisons to the traveling longitudinal wave in Figure 4. Consequently, only the trignometric function is shown consistently in the figures. Although not shown, similar results were obtained for Panel 2.

An unmistakable feature of the measured subsidence, shown in Figure 4 is the considerable variation of its magnitude along the length of the panels. Wile some of this scatter may be atrributed to variations in geological conditions, it also may be related to the rather large variation in the extraction thickness that invariably occurs during mining. In the case of Panel 2, the records of the extraction thicknesses show that it varied from 2.9 to $2.1 \mathrm{~m}$ for a mine in which the nominal extraction thickness is quoted as $2.1 \mathrm{~m} .14$ Moreover, the trend of the actual thicknesses corresponds to the trend of subsidence measurements.

Schmechel et al ${ }^{13}$ determined a number of precisely measured development profiles over a relatively short base in panel.2. These data and the profile function curves are compared in Figure 5 . Basically these data confirm our earlier observations except for some important differences. Here, the development curves are nearly antisymimetric and conform much more closely to the profile functions in the lip of the trough.

Time Dependence of subsidence: It has been recognized that in addition to the instantaneous subsidence, a time-dependent phenomenon also occurs. An analysis using profile functions fundamentaliy treats only the time independent portion of the response. In our analysis, we will make use of this fact to show the nature of the time-dependent portion of the subsidence process. Because of the finite and often discontinuous face advance rate, the time-independent instantaneous response acting alone will yield a time-correlated development curve. This curve results from pseudo time-dependent behavior. A simple relation can be derived for this curve through the profile functions since they are, by definition, time-independent. If the profile function, for example the trigonometric form, described in the instantaneous part of the subsidence, then a straightforward transformation is possible. The horizontal 


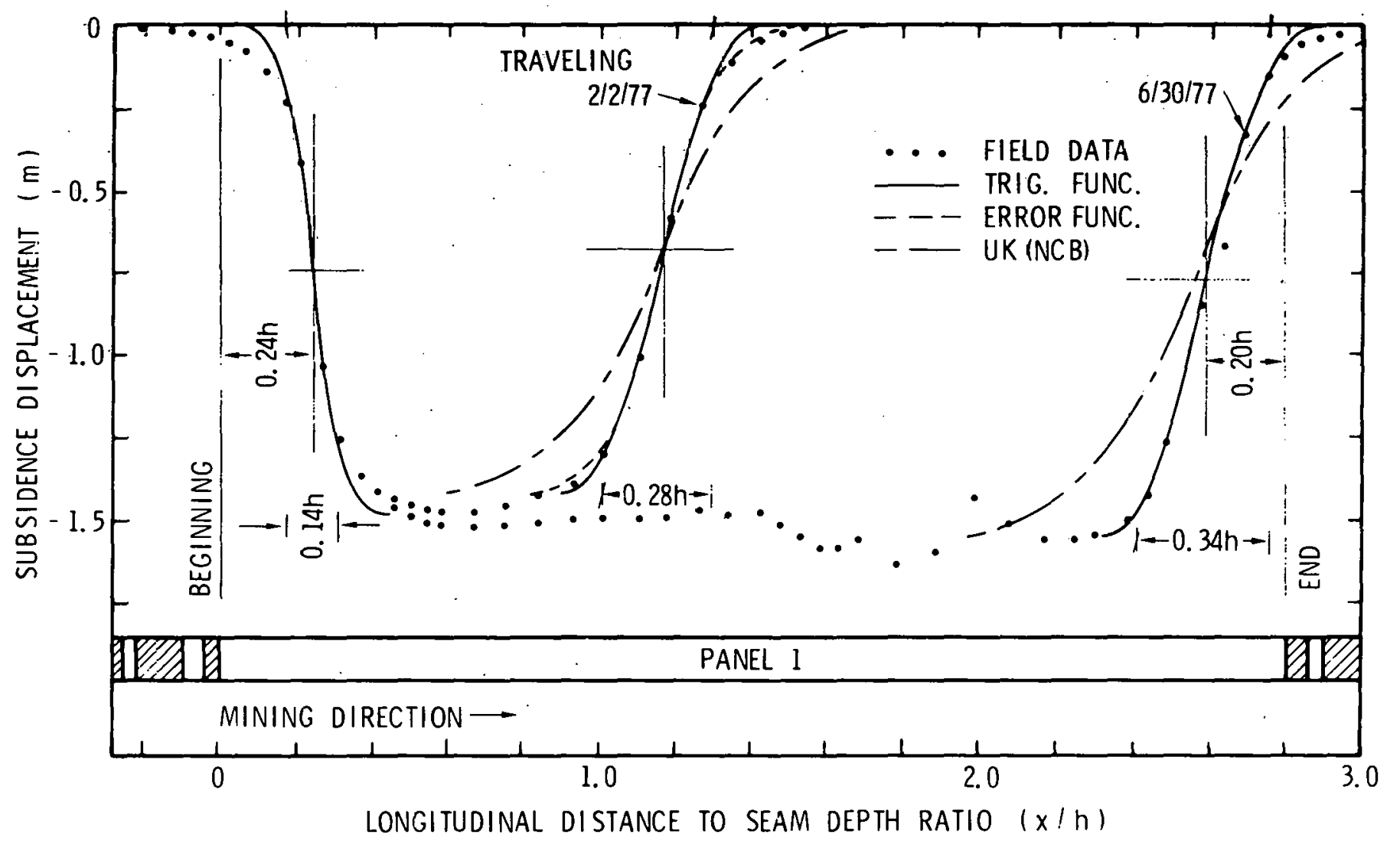

Figure 4. Comparison of the Measured Longitudinal Profiles from Old Ben Panel $I$ and the Empirical Results. After Munson and 


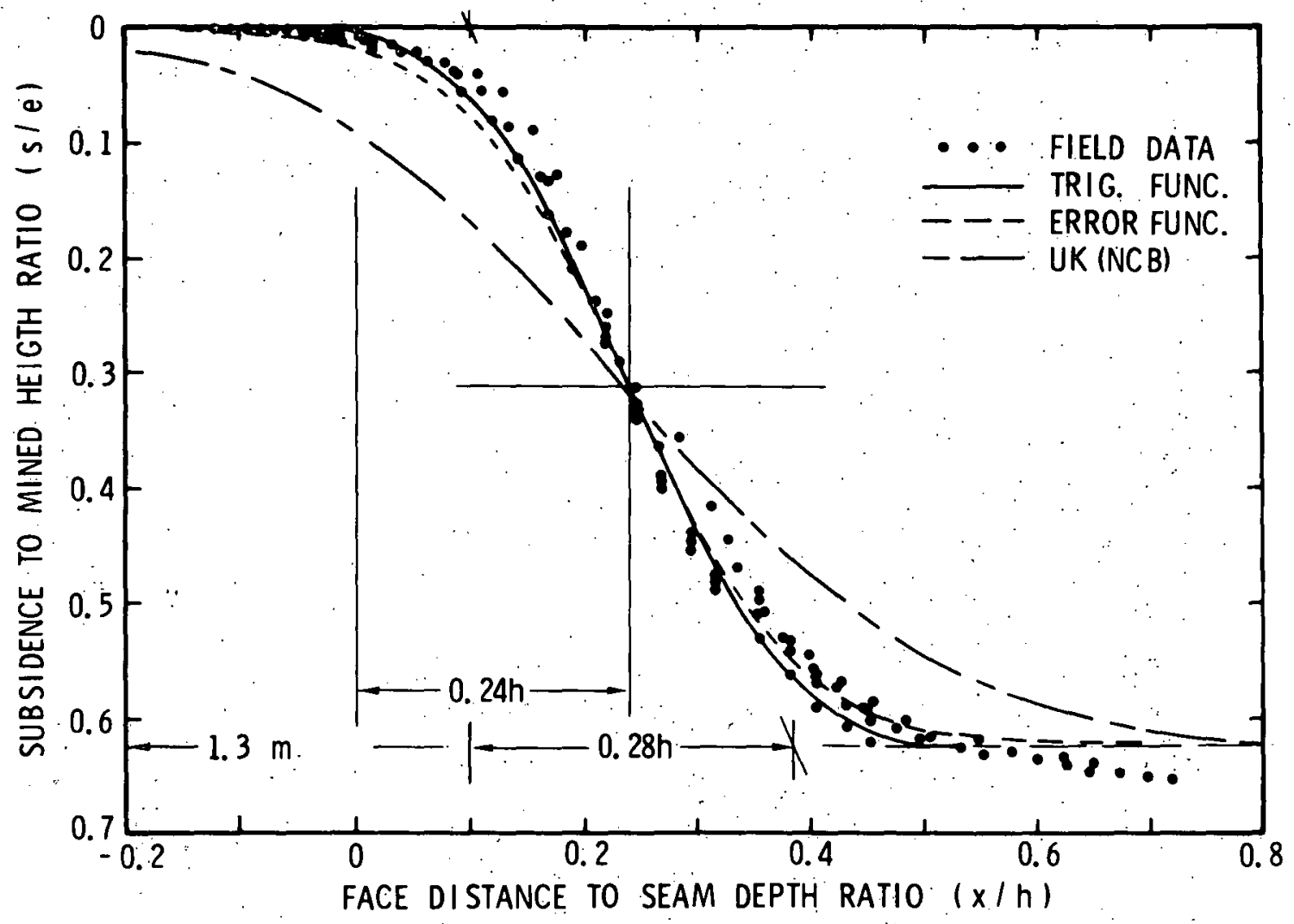

Figure 5. Analysis of Empirical Methods for Development Curves from old Ben Panel 2 (Data of Schemchell3:). After Munson and Eichfeld. 2 
position of the face is given by

$$
x=\int_{0}^{\infty} v(t) d t=\bar{v} t
$$

where $v(t)$ is the face velocity history and the real time integration range is for that time where the face is within $+B h$ to $-B h$ of the observation point. For a non-asymptotic function, Equation 2 becomes

$$
s / s_{m}=1 / 2\left[1-\frac{\bar{v} t}{B}-\frac{1}{\pi} \sin \left(\pi \frac{\bar{v} t}{B}\right)\right] \text {. }
$$

We can plot this result for the time-correlated development cures obtained by Schmechel et al13 on the illinois mine, as shown in FIgure 6 .

Comparing the time-independent calculation with the measured profiles in Figure 6 , one notices significant differences. THese differences are most clearly illustrated at the point where the face advance was first temporarily stopped. Here the field data show that subsidence continues even though the face has stopped. An analogous behavior was noted on the time scale of individual cutting and noncutting shifts at the Bardon Mill and the Blaenavon collieries. 15 Further, the continued trough deepening subsidence at late times, which demonstrates the same rate effect, can be seen in Figure 5 . Such observations of a time-dependent component of subsidence are well recognized; yet this behavior is not normally treated in current analyses. Shoemaker Mine: The European methods were also tested on the two longwall panels from the Shoemaker mine. The mine is located in Northern west Virginia and is operated by the Consolidated coal Company. A nominal $1.7 \mathrm{~m}$ of coal was extracted from both panels. Panel I is $122 \mathrm{~m}$ wide and its depth varies from $198 \mathrm{~m}$ to $213 \mathrm{~m}$. Panel II, located approximately $1.6 \mathrm{~km}$ from Panel I, is $183 \mathrm{~m}$ wide and its depth varies from $122 \mathrm{~m}$ to $213 \mathrm{~m}$. The transverse profiles toward virgin territory), reported by ADamek and Jeran, 4 are shown in Figures 7 and 8. The maximum subsidence recorded for Panel I was $0.9 \mathrm{~m}$ and for Panel Il was $1.0 \mathrm{~m}$.

The empirical fits to these profiles are also shown in Figures 7 and 8 . 


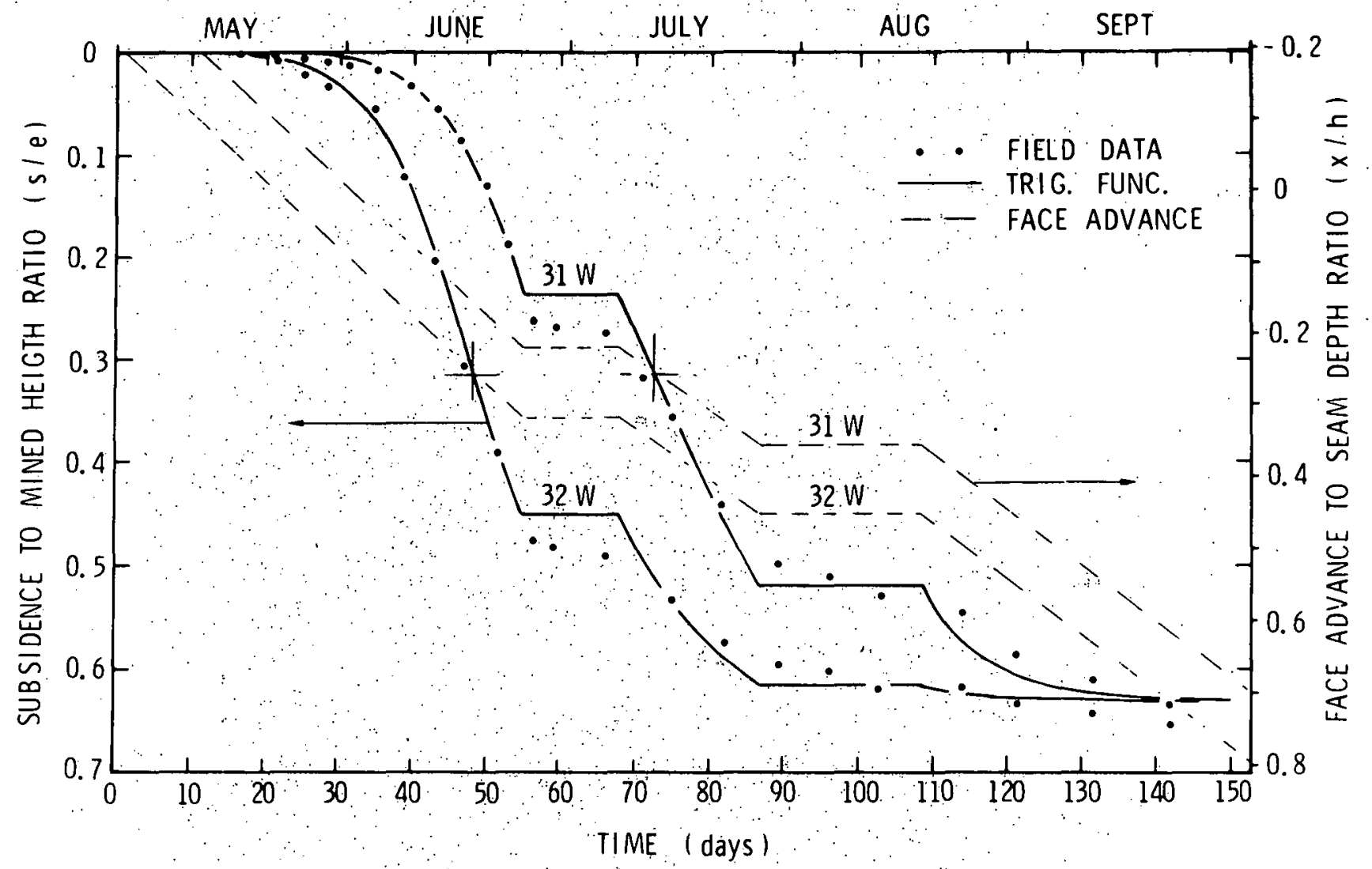

Figure 6. Analysis of True and Pseudo Time-bependent Effects on the Time-Correlated Development Curves, from old Ben Panei 2. After Munson and Eichfeld.2 


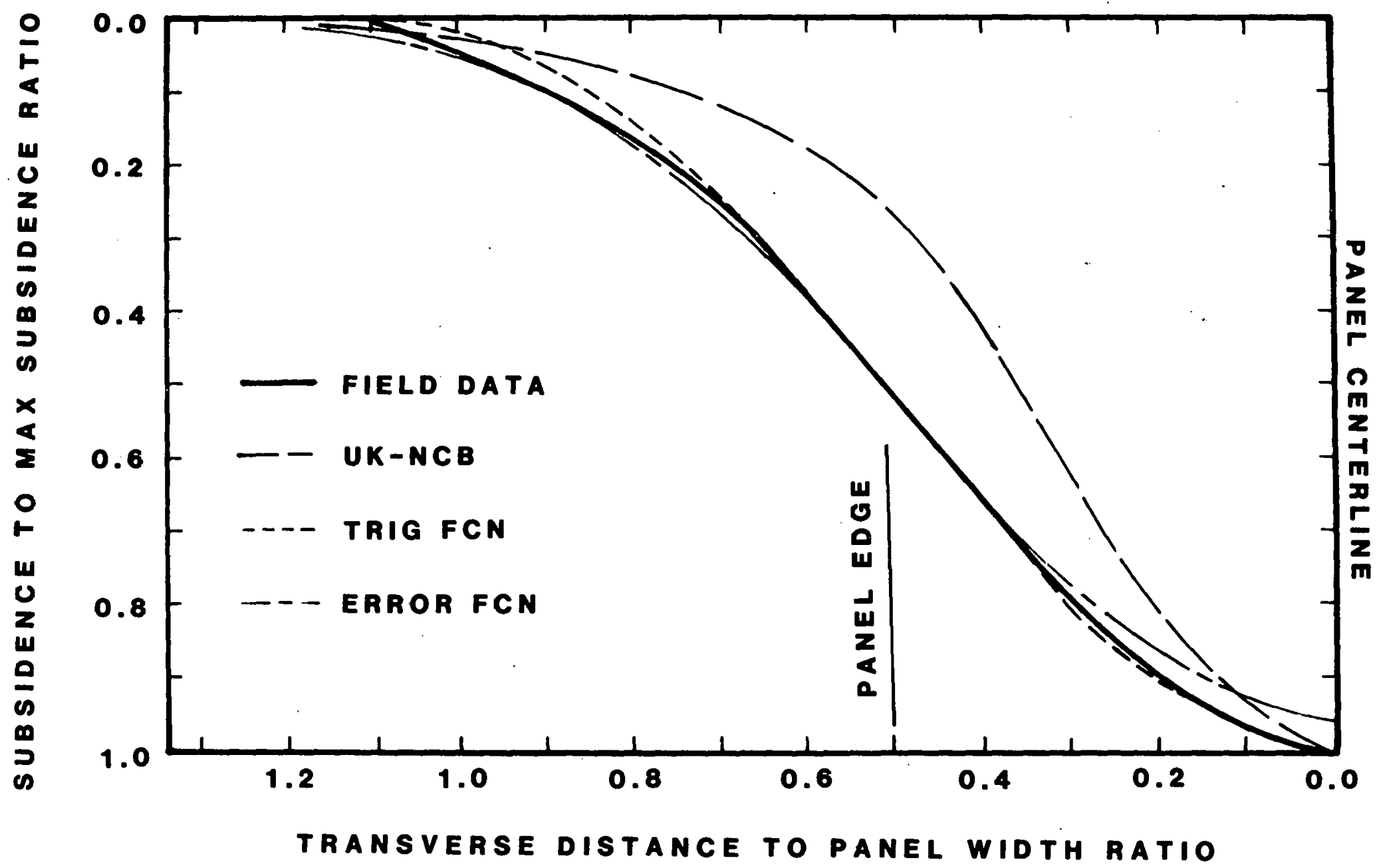

Figure 7. Comparison of the Measured Transverse profile for shoemaker Panel I and the Empirical Results (Data of Adamek and Jeran4) 


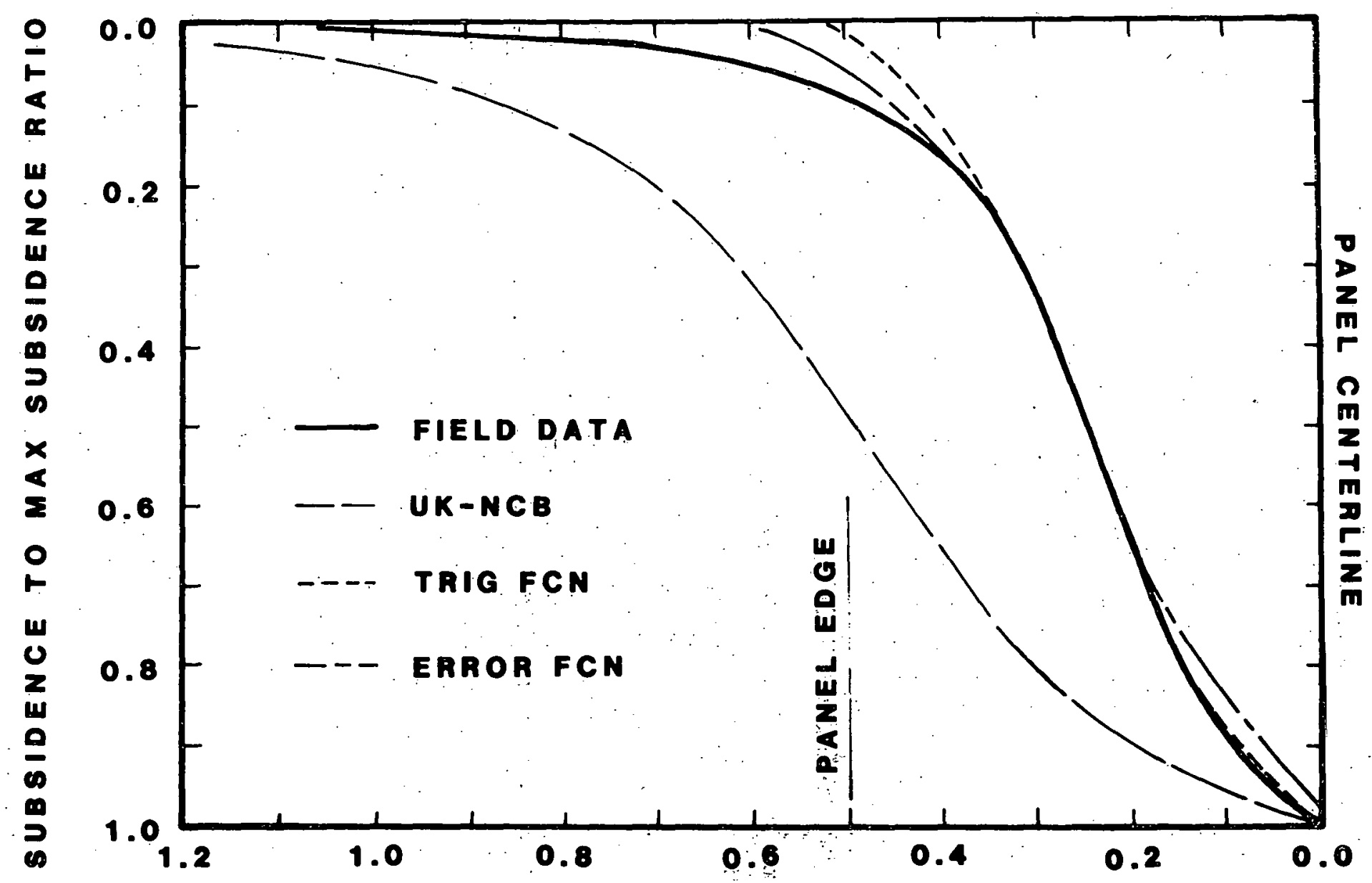

TRANSVERSE Distance to PANEL WIDTh RATIO

Figure 8. Comparison of the Measured Transverse Profile for Shoemaker Panel. II and the Empirical Results (Data of Adamek and Jeran4) 
As shown in this comparison, the profiles behave quite differently. For Panel I, the profile is spread comparatively wide with respect to the NCB predictiọn, whereas for Panel II, the profile is very narrow with respect to the NCB prediction. As the NCB norm normalized the mine geometries, the difference between the profiles is a significant feature that is not a result of slightly different mine geometries. The same result is obtained by comparing the profile function range parameter $B$ for the error function fit, Eq. 1, and the trignometric fit, Eq. 2. Moreover, the comparison of these profiles by Adamek and Jeran ${ }^{4}$ with other available profiles shows that these profiles are the extremes for the currently available transverse profiles.

To explain the major variation between these two profiles, the stratigraphy was examined by Adamek and Jeran. 4 Core drilling revealed that the strata above the two panels were composed primarily of shale and limestones (see Figure 9). Below approximately $107 \mathrm{~m}$, the sequences of strata are similar, with Panel II having more limestone than Panel I. Above $107 \mathrm{~m}$, Panel I has a massive block of shale reaching almost to the surface. In Panel II, this block has three major limestone partings. The largest is located about $91 \mathrm{~m}$ below the surface and has an approximate thickness of $9 \mathrm{~m}$.

\section{Influence Functions}

THe influence function analysis of the various case histories are being conducted under Sandia; contract by the University of California, Berkeley. The principle investigators are. N. G. W. Cook and M. Hood. This work is reported in Ref. 10, 16 and in this volume.

\section{SUBSIDENCE MODEL}

While there exists a wide range of opinions on the critical physical features that govern subsidence, 17 it is believed that three primary modes compete with each other to dominate mine collapse and hence subsidence. These primary modes are comprised of two physically analogous failure modes of progressive roof collapse and progressive pillar failure and a third mode of time-dependent deformation or recompaction. Correct description of these 


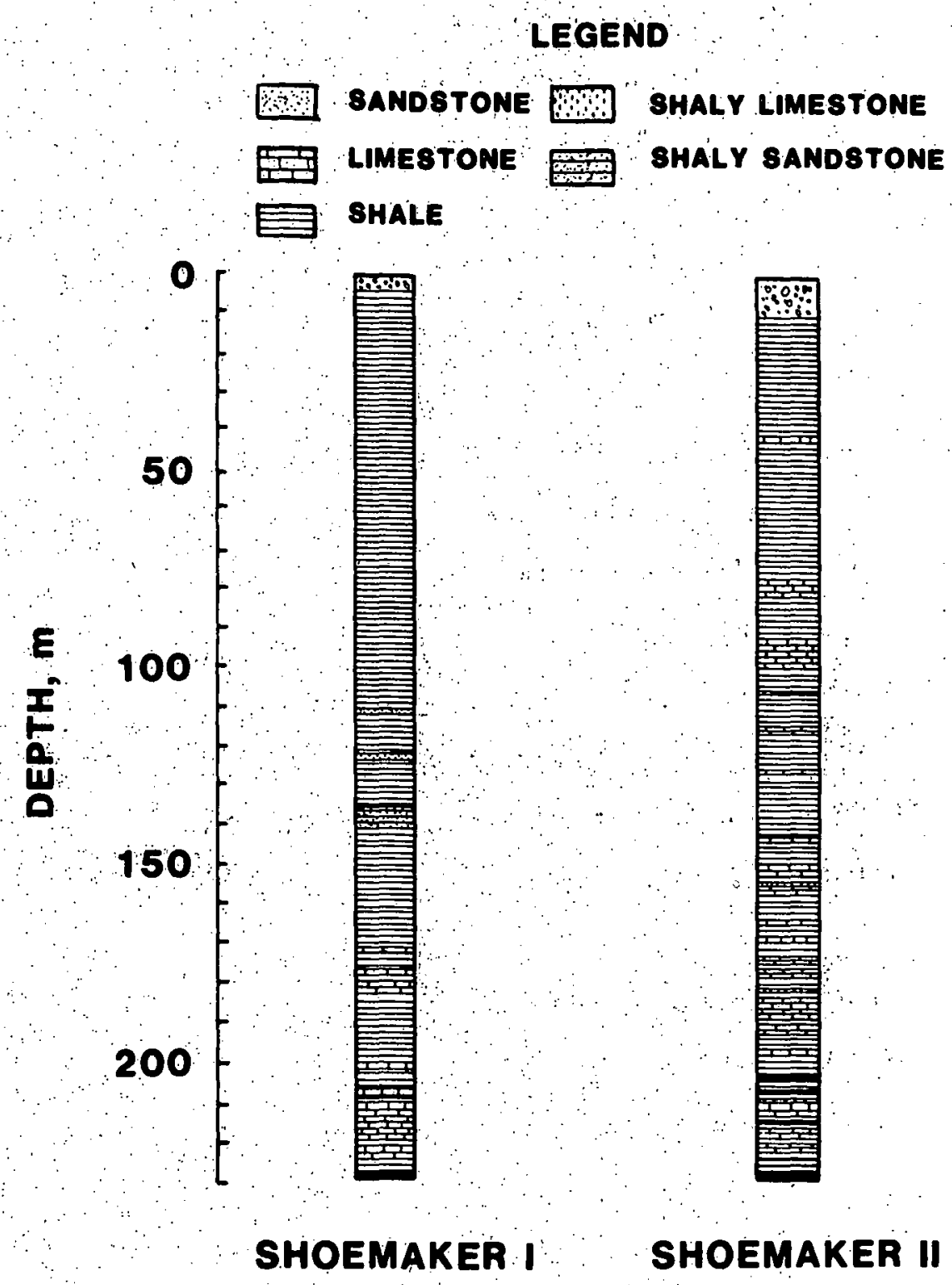

Figure 9. Stratigraphic Logs from the shoemaker Mine (Data of Adamek and Jeran 4 ) 
modes through analytic or numerical models is therefore essential to the development of a subsidence prescriptive capability.

We summarize here the work of Munson and Benzley ${ }^{18}$ who derived a general computational framework for the subsidence process. This framework suggests appropriate functional forms and critical material parameters that influence the subsidence. A simple bulking model is proposed that allows appreciable amounts of volume to propagate from the mine to the ground surface. This volume can depend upon the geology and type of mining.

Historically the early analytic theories, which were largely descriptive, were based on fracture of the overburden and rules for locating the boundarics of the broken material. Evolving mathematical concepts soon forced theoretical developments away from the treatment of fracture and into analytic theories of either broken rock motion or elastic continuum displacement.

It seems appropriate at this stage of the development of prescriptive methods to again look at the natural phenomena occurring during subsidence and model these phenomena, rather than restrict numerical calculations to deformable media models.

Subsidence Framework

Development of the subsidence framework begins with a simple description relating the subsidence volume to the mined volume. The governing equation takes the form

$$
\mathrm{s}_{\mathrm{v}}=\alpha \mathrm{V}_{\mathrm{m}}
$$

where $s_{v}$ is the subsidence volume, $v_{m}$ is the mined volume, and a the subsidence parameter. All material and geometric aspects are contained in $\alpha$, making it an extremely complicated parameter. The problem is to determine the form of this parameter in a physically realistic manner. When one visualizes the mining process, initially stable rooms are formed in which the roof and pillars deteriorate with time and ultimately fail. As the roof blocks fall into the room volume, the material bulks in a manner which depends upon the block size and room dimensions. This bulking will change with time as compac- 
tion of the fallen material occurs under the overburden stress. Schematically this is shown in Figure 10 and is stated in the subsidence parameter as

$$
\left.\alpha=\alpha_{0}+\alpha_{1}(\sigma(t), M(t))+\alpha_{2}(t), M(t)\right),
$$

and

$$
t_{0}=t_{0}(\sigma(t), M), t \geq t_{0},
$$

where $\alpha_{0}$ is a time-independent bulking parameter, $\alpha_{1}$ and $\alpha_{2}$ are time-dependent pendent functions involving time $t$, stress $\sigma$, and a time-dependent material parameter $M$. The initial time, $t_{0}$, is unique for each individual roof layer. This initiation time response for a material is shown schematically in Figure 11.

Initiation Time: All enduring natural and manmade underground structures, including active workings of room and pillar mines, reside in the time domain that is less than the initiation time. The parameters which control the initiation time are the stress and time-dependent material properties. While details of tectonic stress fields, mine opening geometry and roof stabilization practices: affect: the stress field, the principal factor is simply the roof span. Initiation times can be induced, either accidently or intentionally, by increasing the span. Intentionas cases include longwall. mining and. high extraction ratio pillar robbing practices.

The failure criteria are in general not known, and extensive theoretical and experimental efforts are necessary to determine them. In fact, there is probably not a single failure mechanism which controls the process. For example, failure in somewhat ductile rocks may be controlled by stress-rupture properties while failure in brittle rocks may be controlled by stress-corrosion aided fracture propagation.

Roof collapse does not occur simultaneously upward through the roof materials. Rather it progresses upward over some time period. The cause of this progressive failure is the stress history of any given layer, with the most severe stress conditions occuring in the layer with the free surface. Each layer of a given media obeys the same failure curve but with different 


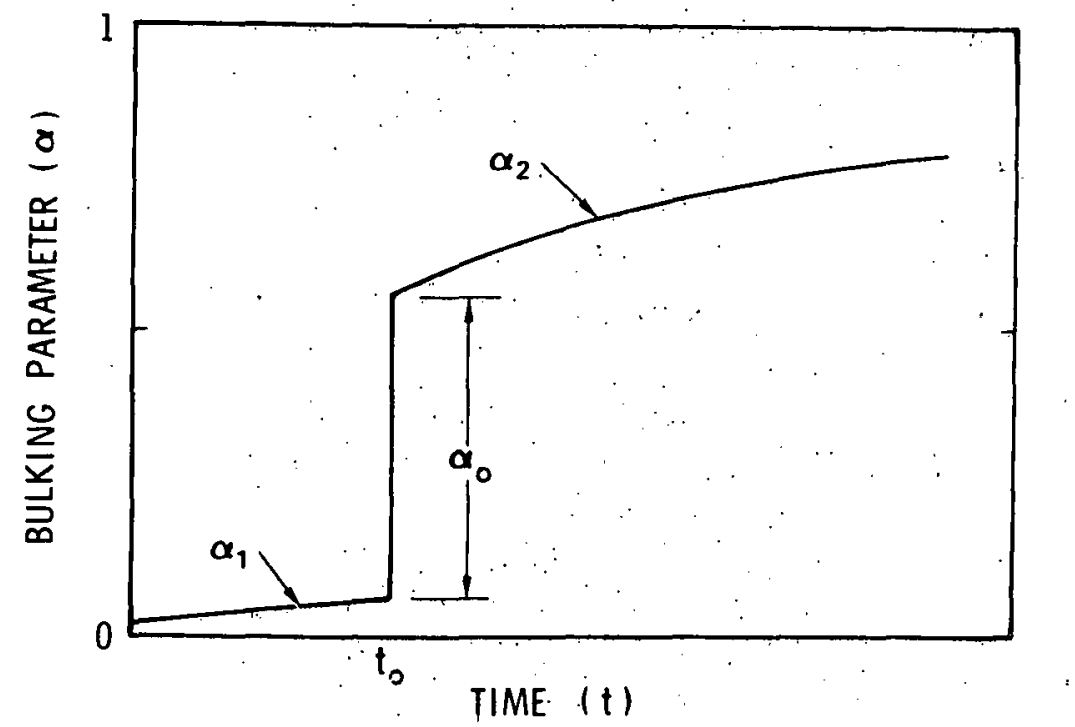

Figure 10. Time Dependence of the Subsidence Parameter. After Munson \& Benzleyl8

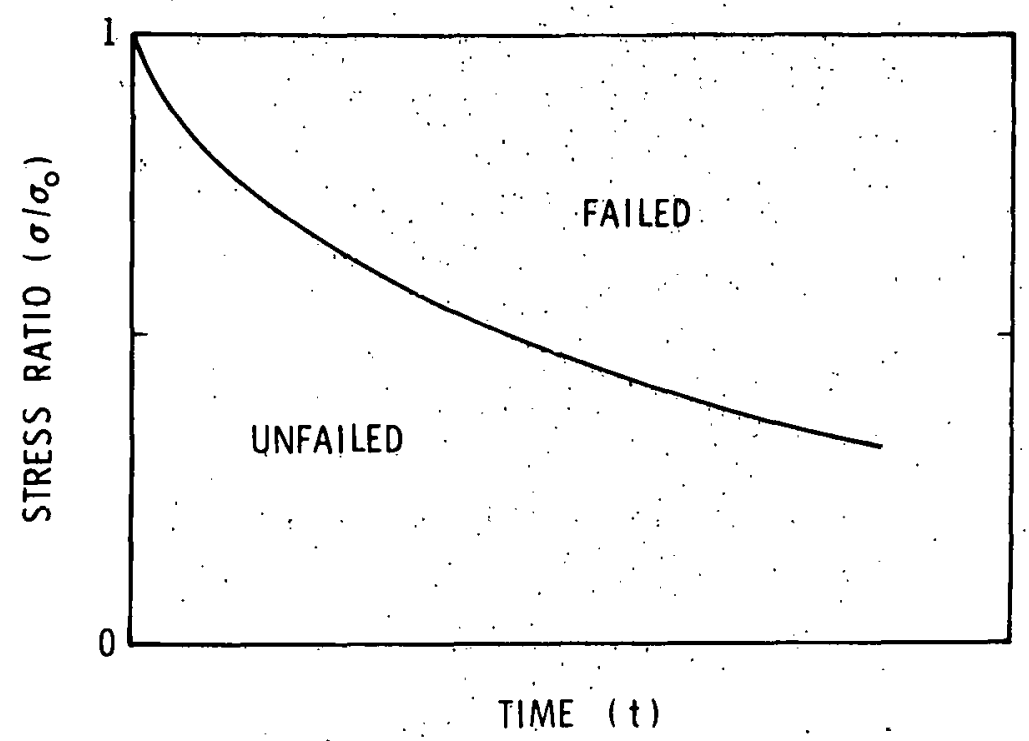

Figure 11. Time Dependence of Material Failure, After Munson \& Benzleyis 
stress histories so that each layer will have a different to value. Thus, roof collapse occurs progressively with layers falling into the opening. Bulking Parameter: The bulking parameter is a time and material independent parameter of great significance. This parameter essentially controls how void volume from the initial mine cavity propagates to the surface. It and the volume fraction of void are related directly; namely, $1-\alpha_{0}$ is the initial volume fraction of void. The parameter is developed from a physical picture of roof collapse just after initiation. At this stage, blocks of characteristic dimension, $b$, fall through a height, $h$ ', to the floor. They fall independently and unstressed. If they fall through a distance equal to several of their characteristic dimensions then the probability of achieving a random orientation is great and the introduction of void space will be madimum. If, however, the block falls through a distance on the order of its characteristic dimension, then the probability of rotation is small and it takes on an orientation similar to its original orientation, with the introduction of little void volume. "For this process the curve shown schematically in Figure 12 is called the void volume distribution function. Here $\mathrm{b} / \mathrm{h}^{\mathrm{c}}$ is the ratio of the characteristic block dimension and the height of the room.

As a layer of material of thickness, $\ell$, falls and bulks, it forms a layer on the floor of greater thickness Thus; the height of the cavity decreases by

$$
\Delta \mathrm{h}^{\prime}=\ell \frac{1-\alpha_{0}}{\alpha_{0}}
$$

which results in each successive layer falling through a smaller distance. Consequently, even for a uniform material, a progressive change in the $b / h$ ' ratio occurs, with an attendant change in the void volume, $1-\alpha_{0}$. Material Response Functions: That portion of the subsidence parameter leading to non-bulking subsidence is composed of various material response functions. These functions may be descriptions of either time-dependent or time-independent mechanisms such as elastic deformation, plastic deformation, creep, and 


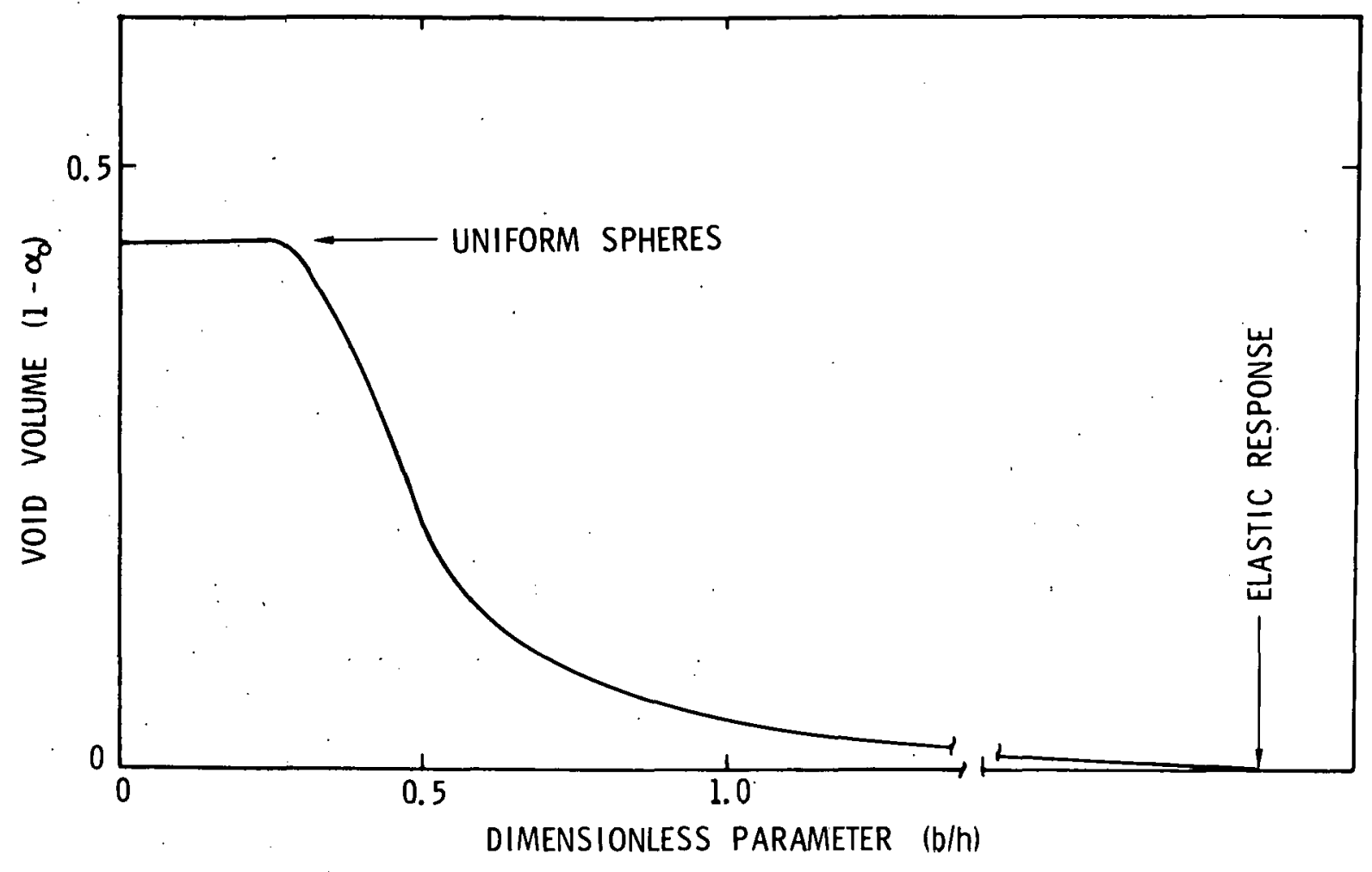

SCHEMATIC OF VOID VOLUME DISTRIBUTION CURVE

Figure 12. Void Volume Distribution Function. After Munson and Benzley 18 
void compaction. In some cases the material mechanism will be the principal subsidence factor from the onset; for example, creep closure of rooms. In other cases the material mechanism will augment collapse and failure modes of subsidence; for example, compaction of rubble. For any given site, the relevant material functions must be determined in order to solve the general subsidence problem.

\section{PHYSICAL SIMULATIONS}

The subsidence above a mine drift involves phenomena that are driven primarily by the force of gravity. The body forces in the overlying strata interactring with the mine geometry create the overburden stress distribution. The horizontal stresses are a result of an interaction of these overburden stresses with the structural configuration, material properties, and tectonic activity. To produce an adequate physical simulation of a full-size prototype structure by using a reduced scale model, the stress field which occurs in the prototype must be duplicated in the model. As described by Bucky, the "... scalar model of any weighty structure will behave like its prototype if the model and the prototype material are the same, and if the effective model weight is increased in the same proportion as its linear model dimensions are diminished. The effect of an increase in weight is obtained by substituting a centrifugal field of force for the gravitational field, the model being placed in a suitably designed centrifuge...19 And, if rocks and soils from the field site are used in the scale model, then regardless of the complexity of the materials' stress-strain behavior, one may reproduce the entire displacement and strain fields, as well as the stress field. For example, a coal mine located $300 \mathrm{~m}$ below ground level may be simulated by a $1 / 100$ scale model that is $3 \mathrm{~m}$ deep and constructed from representative site materials by loading the scaled model in a centrifuge at 100 gravities (100 g's). Additional discussions of this technique are provided by Bucky 20 and sutherland et al. 21

Here we summarize the work of sutherland, Schuler, and Benzley ${ }^{22}$ who used physical models to simulate mine structures. Using Nevada tuff, essentially 
an elastic material, and silica flour, two idealized mine structures were constructed and tested to $150 \mathrm{~g}$ scaling. The failure sequence for one of these models is shown in Figure 13. The model was approximately $266.7 \mathrm{~mm}$ wide and had a drift $152.4 \mathrm{~mm}$ wide and $25.4 \mathrm{~mm}$ high. The $196.9 \mathrm{~mm}$ of overburden was composed of 47 layers of the tuff (each $13.18 \mathrm{~mm}$ thick) and $44.4 \mathrm{~mm}$ of silica flour.

As the number of broken layers increases, the volume (area) into which succeeding layers fall decreases. This bulking process, described by Eq. 8 , can be seen by comparing Figures 13a and 13f. In Figure 13a, the volume into which the first layer falls is $9.8 \times 10^{4} \mathrm{~mm}^{3}$. In Figure $13 \mathrm{f}$, this volume has been reduced to $2.6 \times 10^{4} \mathrm{~mm}^{3}$ (a $75 \%$ reduction in area). To follow this process through the course of the experiment, the open volume (area) was measured from movies of the test after each fall. The results of these measurements are shown in Figure $14 a$ as the percent loss of area (based on the original area) vs the number of broken layers. As seen in Figure 13b, the initial high loss of volume is due to "bridging" of broken strata along the side walls of the drift. Subsequent failure usually continued to reduce this volume, the exception being when a falling layer broke some of the bridges below it, thus producing a more compact debris pile and thereby increasing the volume into which subsequent failed layers fell. Figure $14 \mathrm{~b}$ poses this area loss in terms of the bulking factor.

\section{NUMERICAL SIMULATIONS}

For this discussion, we will illustrate our numerical techniques by analysing the physical model described earlier and the two longwall panels from the Shoemaker mine. The unique feature of both calculations is a description of the behavior of the failed material, or rubble, including such features as falling, bulking and recompaction. This analysis is unique to subsidence modeling and has received very little attention, particularly in finite element analysis. Here we have used a continuum approach, the Rubble model, 23 to describe the rubble motion. This permits rapid calculations; 


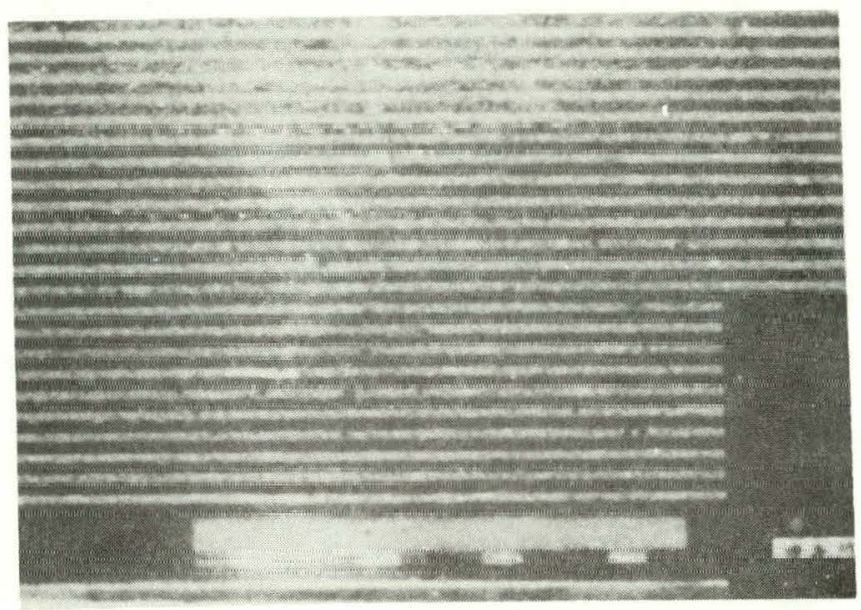

a. Pretest

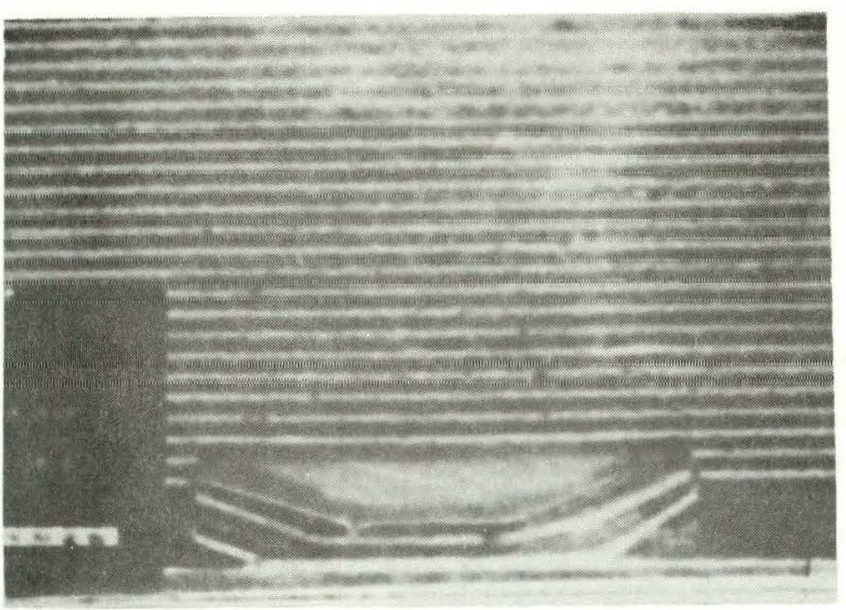

b. Pattern at $79 \mathrm{~g}^{\prime} \mathrm{s}$

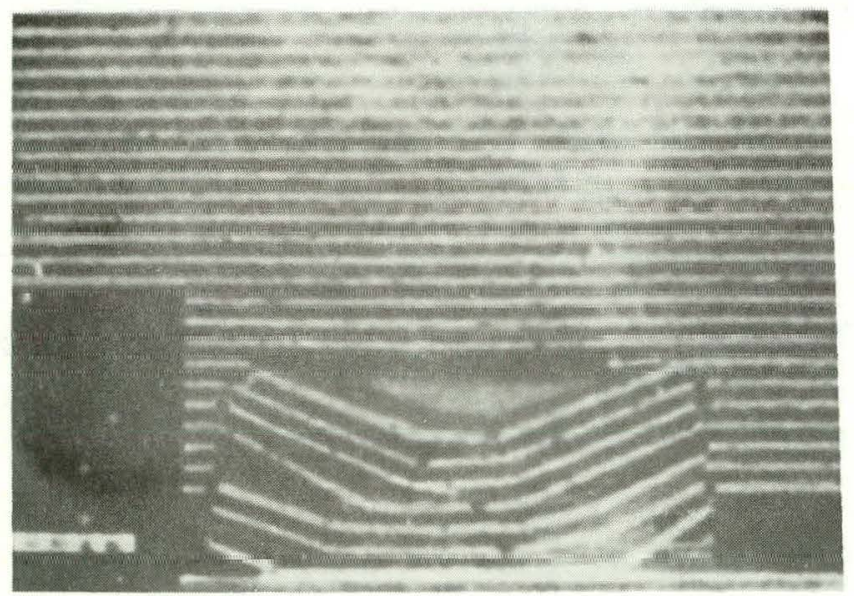

c. Pattern at $84 \mathrm{~g}^{\prime} \mathrm{s}$

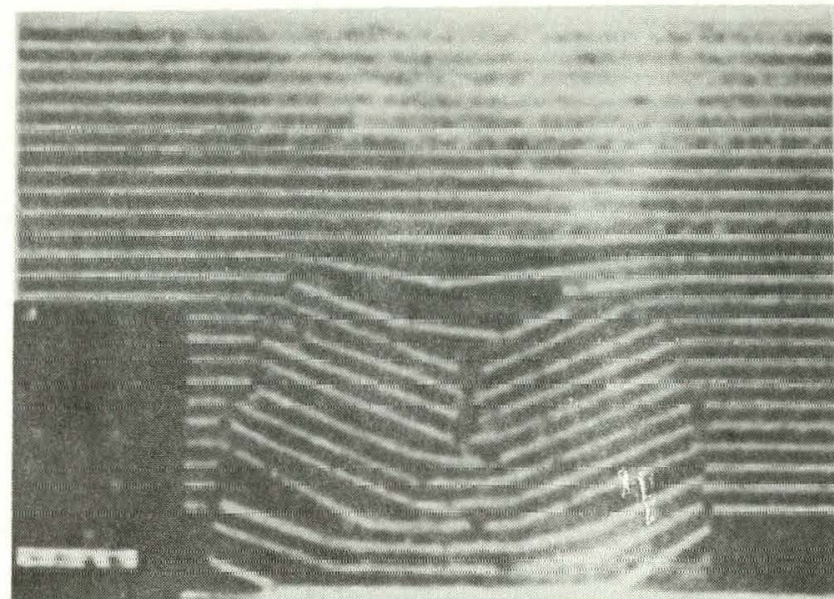

d. Pattern at $98 \mathrm{~g}^{\prime} \mathrm{s}$

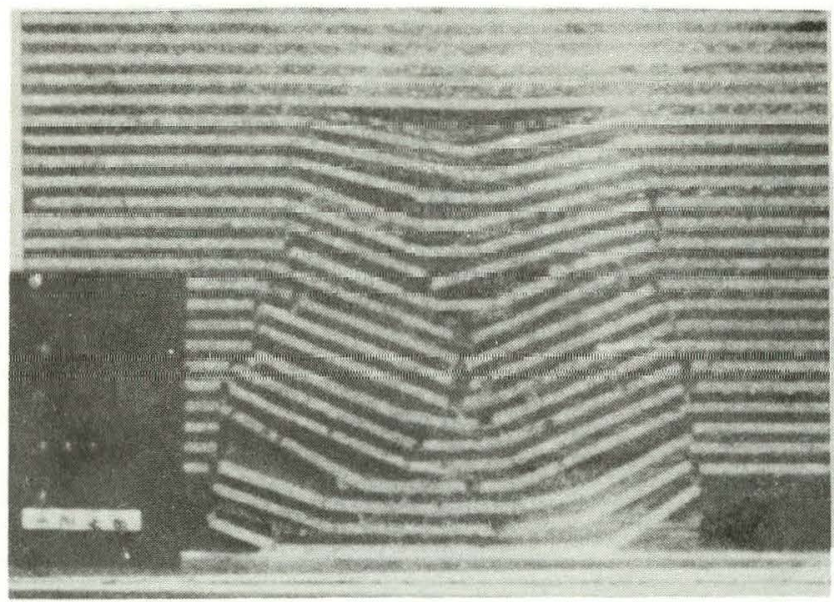

e. Pattern at $107 \mathrm{~g}^{\prime} \mathrm{s}$

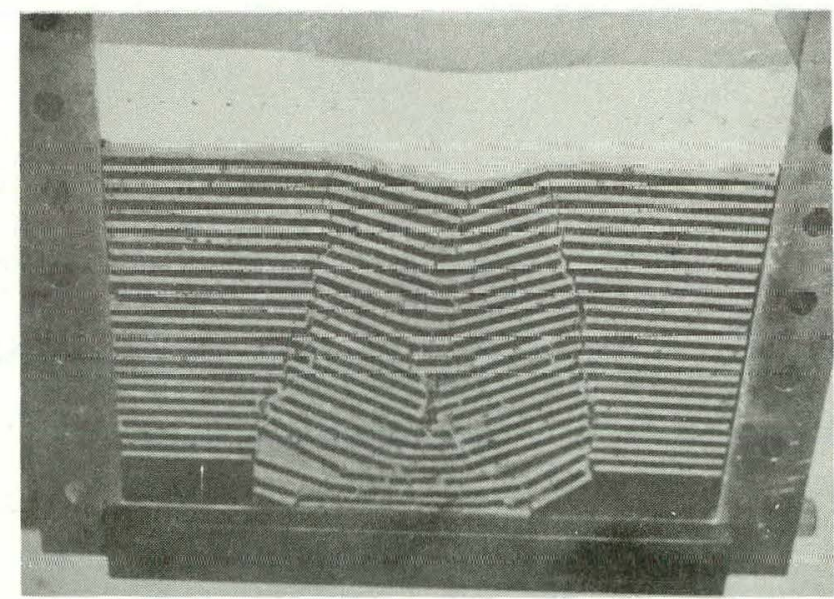

f. Post Test

Figure 13. Faịlure Patterns in an Idealized Mine Structure Made From Nevada Tuff (alternate layers painted black for optical clarity) and Silica Flour. After Sutherland, Schuler, and Benzley $22^{2}$ 


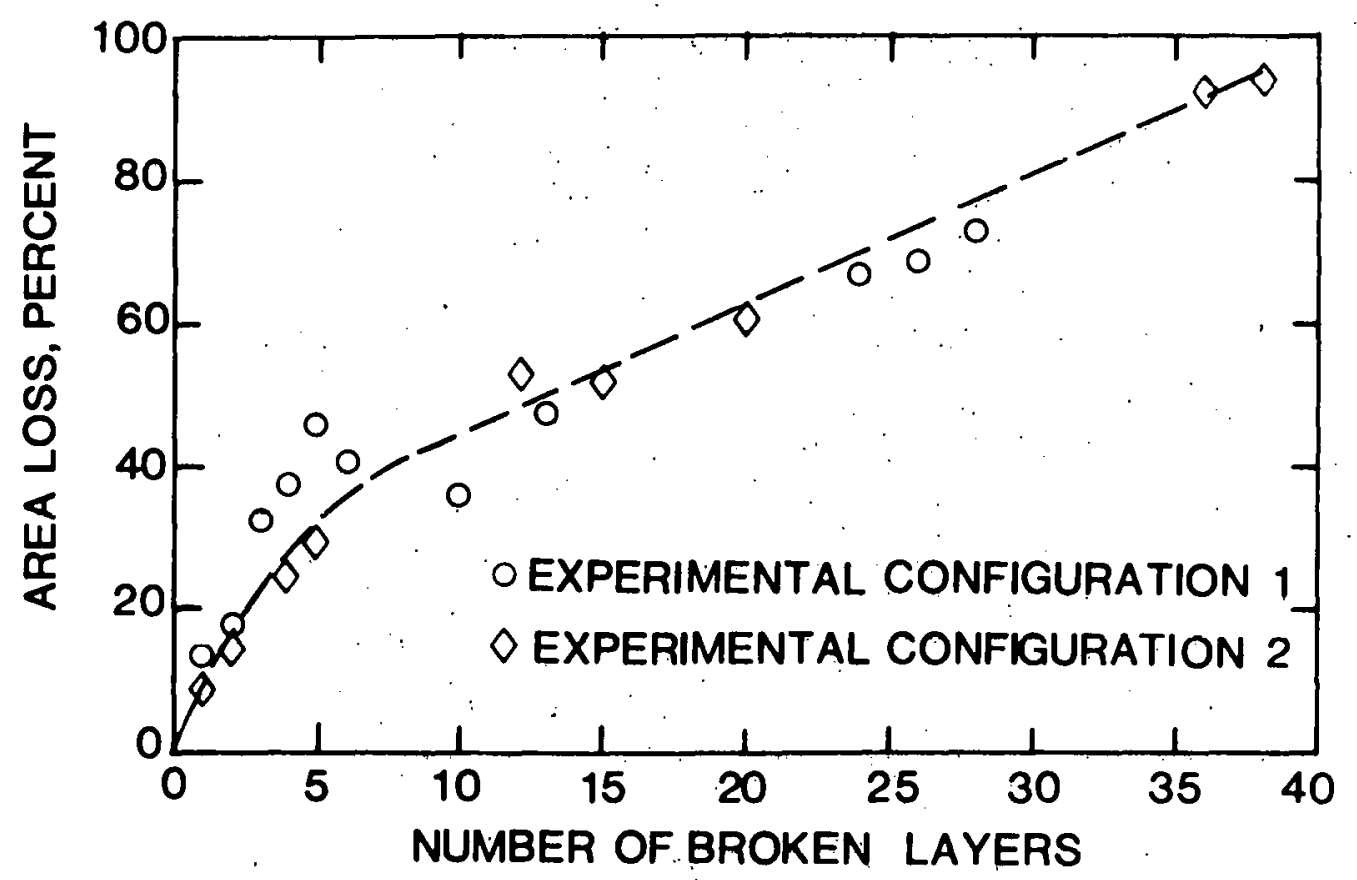

a

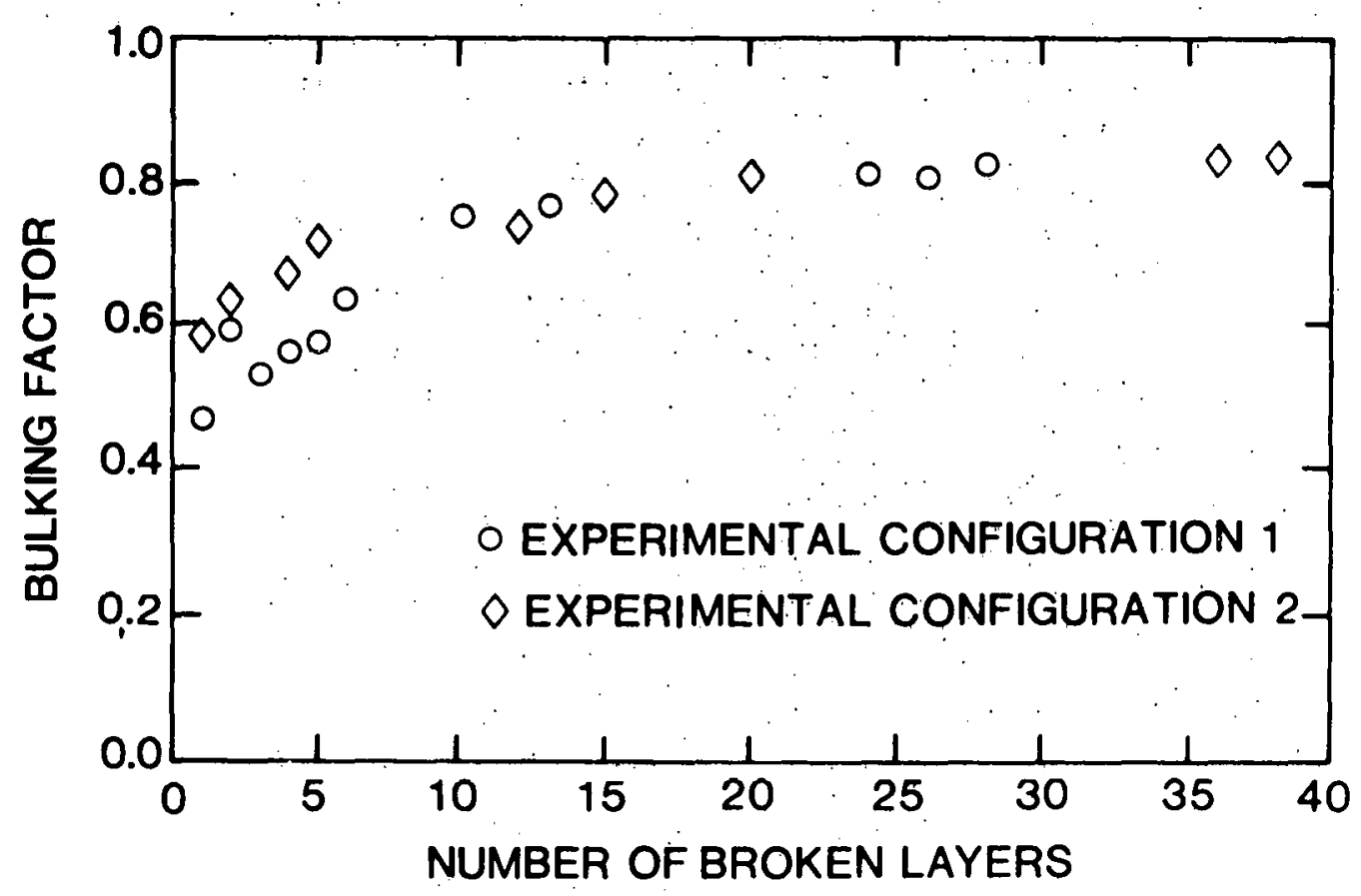

b

Figure 14. Area Loss and Bulking Factor in Two Idealized Mine Structures. After sutherland, Schuler, and Benzley 22 
however, it lacks the detailed description of other approaches which consider discrete joints, blocks," etc. "In this model the failure of an element is followed by the distension of the element until it strikes the mine fioor or the top of the rubble pile: The element can subsequently recompact as additional loads are superimposed upon it.

Simulation of the Physical Model

The first step in the analysis of the physical model shown in Figure 13 is to predict the failure sequence of the layers. This analysis, is complicated by the large number of interfaces which can possibly separate or, if in contact, can either slip or stick. The non-iinearities resulting from this interface behavior require an iterative analysis which is both time consuming and costly. Ideally we would like to have a simple failure criterior which could be used with the Rubble model. Indeed, some of the initial modeling of the experiments assumed a simple maximum tensile stress failure criterion and no slip between layers. However, in order to produce failure at the observed g loads, the failure stress level had to be reduced by a factor of ten from that calculated from the single beam experiments. Furthermore, the arching predicted by this calculation did not match that observed in the experiment. To investigate the behavior of the layers immediately above the mine opening, a calculation using the JAC code ${ }^{24}$ was performed. Figure 15 shows the results of this calculation. sliding interfaces were incorporated between each of the five layers, and, as, the greatly magnified distorted mesh plot shows, both separation and slippage occur: This çalculation required such a large amount of computer time that the incorporation of additional layers would be prohibitive unless a more efficient iteration algorithm can be devised. A detailed examination of the contact forces between the layers shows that the lowest layer is loaded only by its weight. Thus, in the context of beam theory, it is loaded as shown in Figure 16a. However, the next layer up in the strata is loaded as shown schematically in Figure 16b. Separation does not occur along the entire length of this beam, thus a portion of this beam 


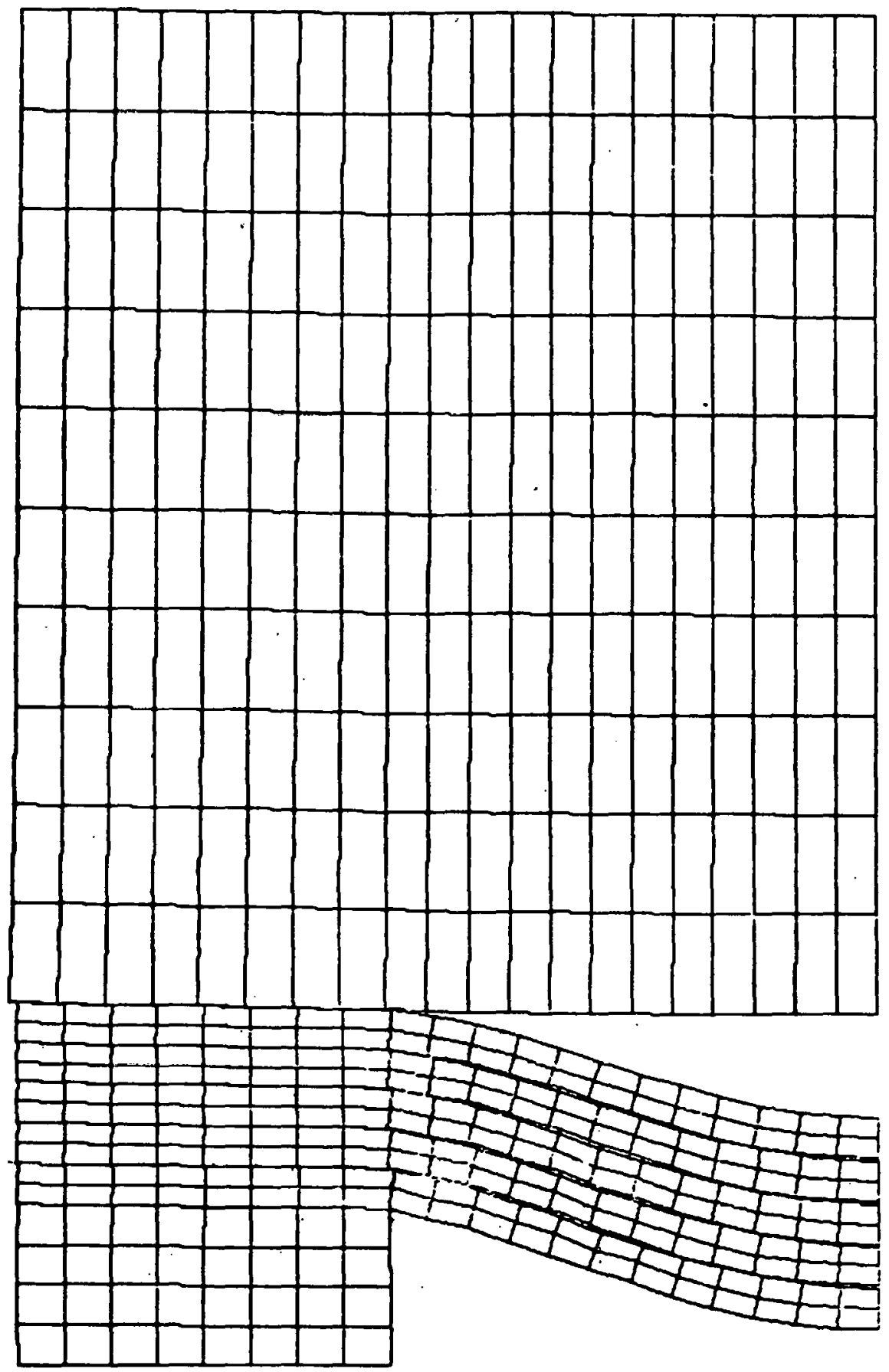

Figure 15. Multiple Slab Calculation for the Idealized Mine Structure with Friction and Separation (Deflections greatly magnified). After Sutherland, Schuler, and Benzley 22 


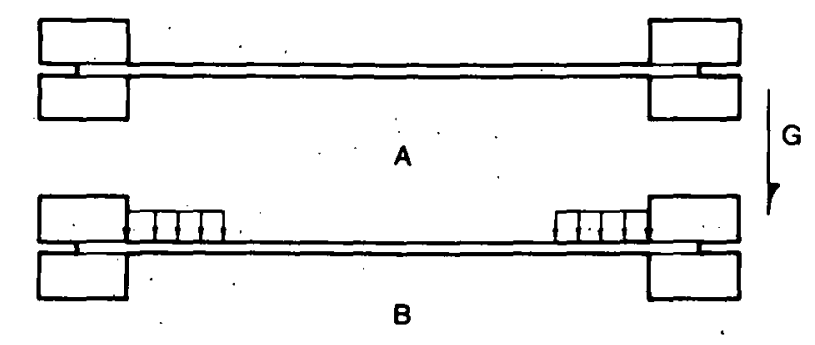

Figure 16. Schematic Diagram of a) Single Beam Loading Condition and b) The Likely Loading conditions on Separated Beams in the Idealized Mine Structure. After Autherland, Schuler, and Benzley 22 
near each end bears load from the layer above. This loading condition produces a more severe stress state than would result if the beam were loaded only by its weight. To determine the distribution of these loads on a given layer would require an iterative solution for the entire model which does not appear feasible at this time.

Thus, at this time, it must be concluded that an adequate technique for predicting the failure sequence observed in the experiments is not available. However, if the failure sequence observed in the experiments is input into the Rubble model, it is possible to determine if the second step of the analysis procedure (i.e., the prediction of the rubble motion) can be considered adequate. This calculation should be viewed as a duplication but not a prediction of the failure sequence. A coarse grid was used in these calculations and the failure was assumed to occur at five g levels as shown in Figure 17 . Note that the rubble elements are bulking after failure. This bulking results in the final depth of the subsidence trough at the surface being significantly less than the initial height of the drift. A comparison of the observed surface being significantly less than the initial height of the drift. A comparison of the observed surface displacement and that predicted by the Rubble model is shown in Figure 18. Here it is seen that excellent agreement can be achieved and it appears that this model provides an adequate treatment of the rubble motion.

In the calculations with the Rubble model unfailed regions are treated as a linearly elastic continuum (i.e., there are no interfaces along which separation or slip can occur). It is interesting to examine the stress field predicted in the unfailed regions at $g$ levels just prior to failure. Figure 19 is a plot of the zero vertical stress contour at various $g$ levels. As a first approximation the layers in the region below this contour could be considered to have separated. If this is the case, the contours suggest that complete scparation does not occur along the length of the lowermost beam. Figure 20 shows the contours of the horizontal stress in the unfailed 


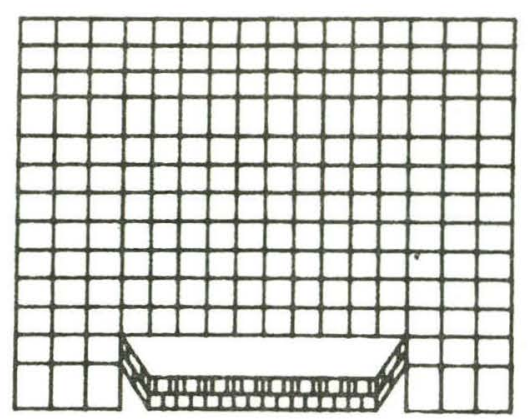

$76 \mathrm{~g}$

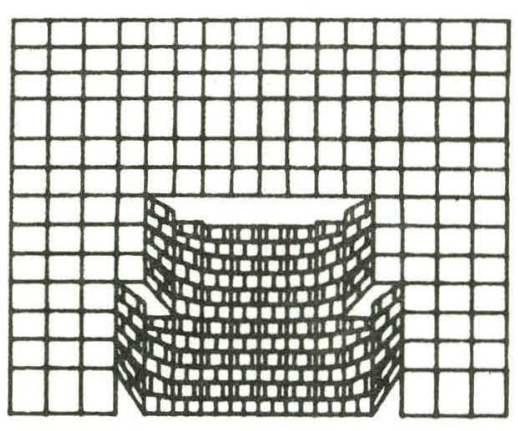

$98 \mathrm{~g}$

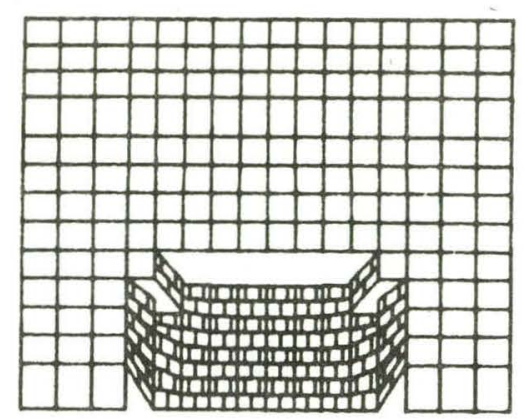

$85 \mathrm{~g}$

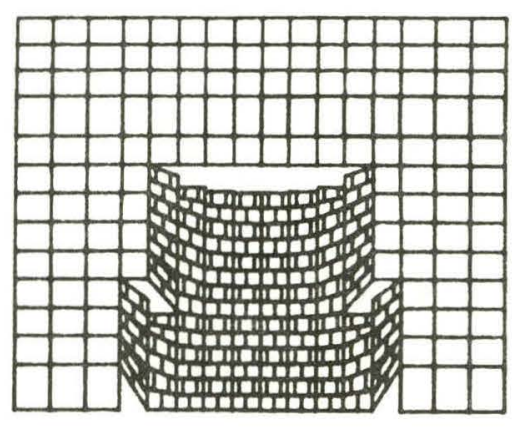

$107 \mathrm{~g}$

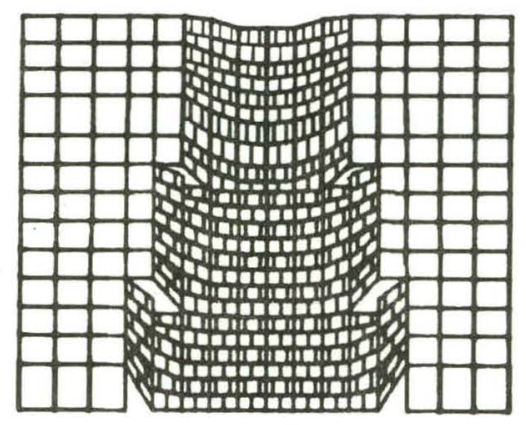

$109 \mathrm{~g}$

Figure 17. Failure Sequence in the Idealized Mine Structure Showing Rubble Formation at the Indicated $g$ Level. After Sutherland, Schuler, and Benzley $2 \dot{2}$ 


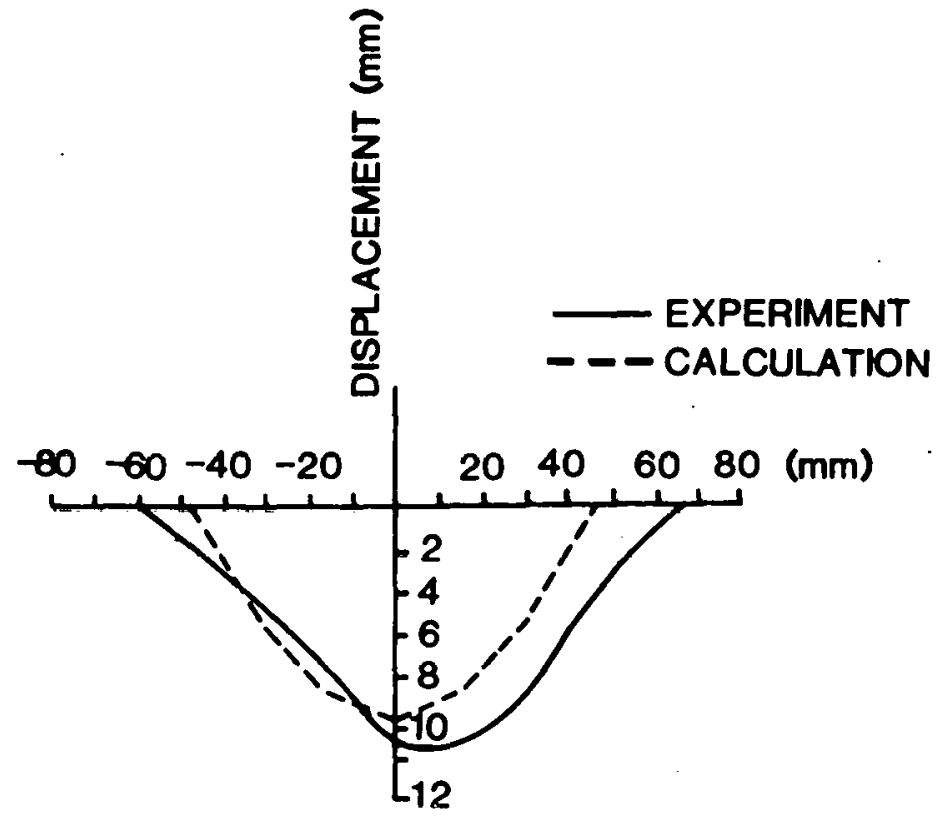

Figure 18. Comparison of the Experimental and Calculated Subsidence Trough Formed in the Idealized Mine structure. After Sutherland, Schuler, and Benzley 22 


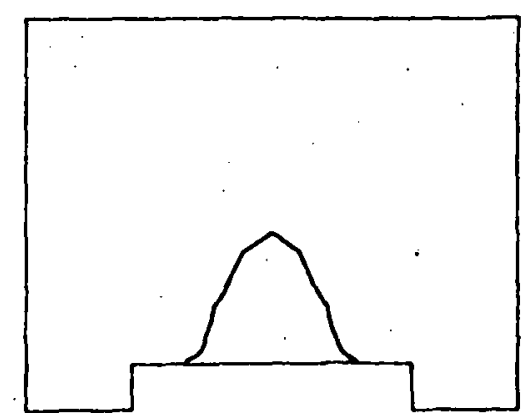

$75 \mathrm{~g}$

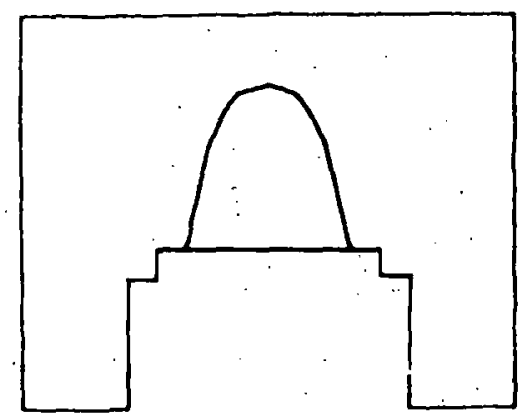

$97 \mathrm{~g}$

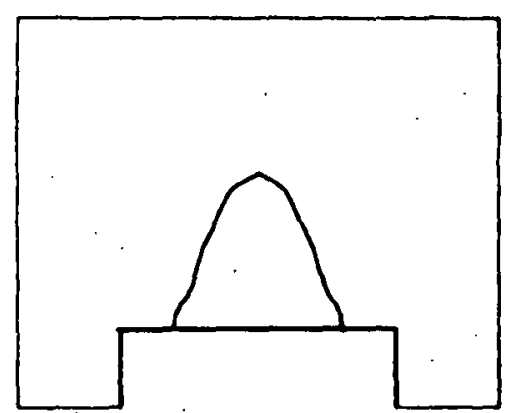

$84 \mathrm{~g}$

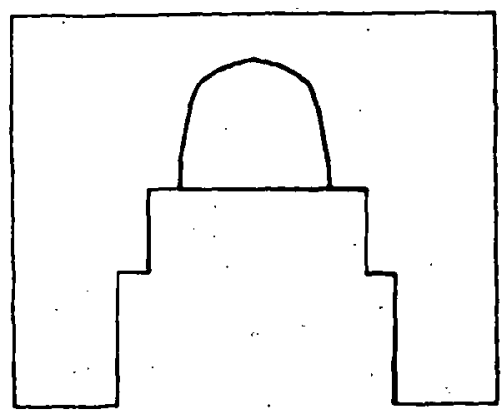

$106 \mathrm{~g}$

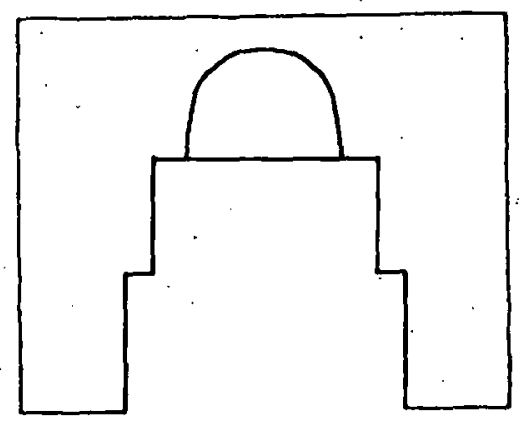

$108 \mathrm{~g}$

Figure 19. Zero Vertical stress Contour as a Function of g: Level for the Idealized Mine Structure (note that the lowest horizontal line of each contour is the location of the lower surface of the failed section). After sutherland, Schuler, and Benzley 22 


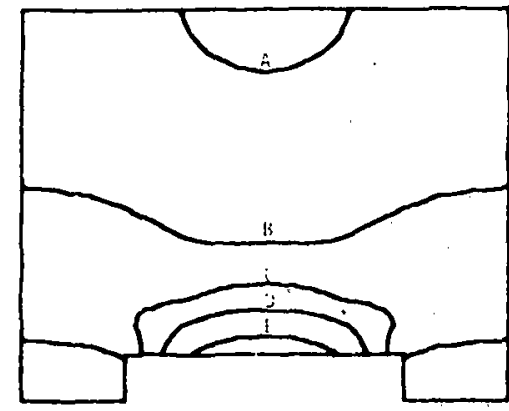

$75 \mathrm{~g}$

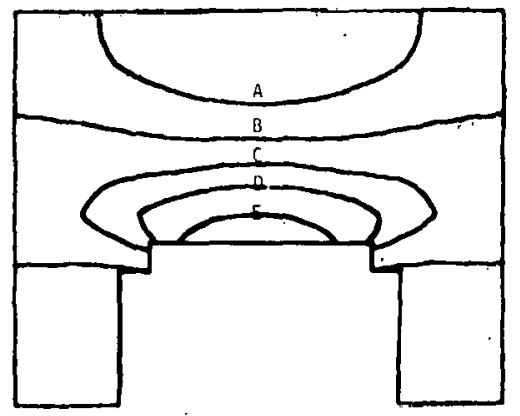

$97 \mathrm{~g}$

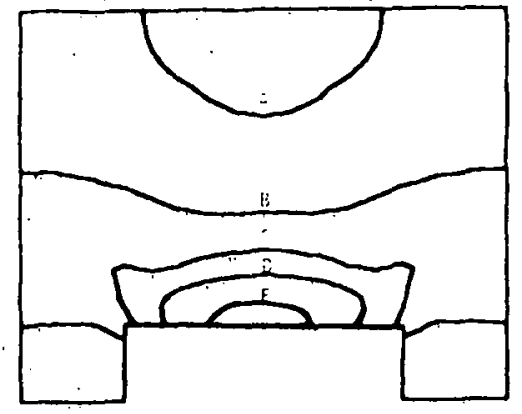

$84 \mathrm{~g}$

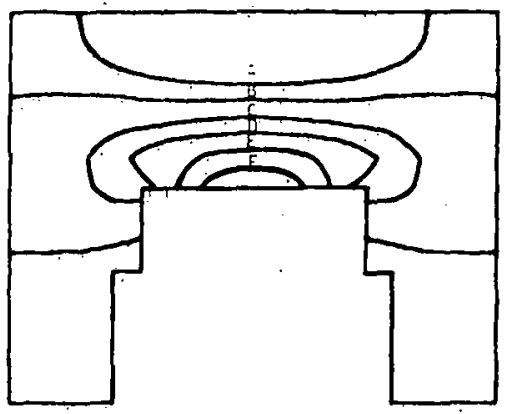

$106 \mathrm{~g}$

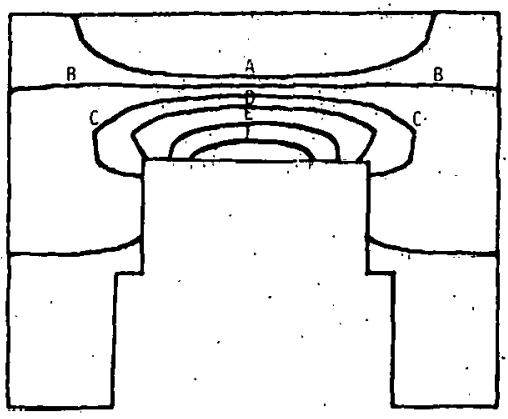

$108 \mathrm{~g}$

Figure 20. Horizontal Stress Contours in the Idealized Mine structure Immediately Prior to the Resulting Failure condition shown in Figure 17 (i.e., stress shown in Part $A$ of Figure 17). Contour Levels $\mathrm{A}=-10.0$ psi $(69 \mathrm{KPa}), \mathrm{B}=0.0, \mathrm{C}-10.0$ psi $(69 \mathrm{KPa}), \mathrm{D}-20.0 \mathrm{psi}(138 \mathrm{KPa}), \mathrm{E}-30.0 \mathrm{psi}(207 \mathrm{KPa})$, $F-40.0$ psi $(276 \mathrm{KPa})$. After Sutherland, Schuler, and Benzley 22 
region just prior to failure. The maximum stresses occur at the centerline of the lowest fiber of the lowest unfailed element. These predicted stresses are between 4 and 10 times less than the nominal tensile strength of the tuff and they show a systematic increase with increasing g level. Clearly the assumption of a constant failure strength reduced from the actual strength would not adequately predict the onset of failure.

Remarks: To help place these analyses in perspective we want to discuss them in a different context. In the layered analysis, we have shown that the "laboratory" material properties may be used to predict the correct failure sequence if the joints in the rock mass can be and are handled explicitly in the calculations. However, if these "large-scale rock mass irregularities" are smoothed over as with continuum calculations, then the laboratory properties do not yield correct predictions. One method that has been proposed to deal.with this inadequacy in these calculations is to reduce the laboratory properties by some reduction factor. Bieniawski ${ }^{25}$ has tied such a reduction factor to a "Rock Quality Designation" (RQD), and Kulhawy ${ }^{26}$ has shown how the RQD can be used to determine the reduction factor for jointed systems. This result has also been observed by Barton et $a^{27}$ in different geological settings.

Simulation of the Shoemaker Mine. Earlier in this report we discussed the application of European empirical methods to two longwall panels from the Shoemaker Mine. In this section we will detail some preliminary results obtained using the Rubble model to describe the differences in the subsidence profiles over these two panels. The finite element mesh which was used in the calculations is shown in Figure 21. This mesh geometry was used to model both the shoemaker I (SI) panel and the Shoemaker II (SII) panel by changing the extraction width, w. The stratigraphy over these two panels as reported by Adamek and Jeran 4 is also shown in Figure 21 . In examining the stratigraphy we note a large number of layers and the question naturally arises, "How many of these layers need to be included in the model?" our first calculation 

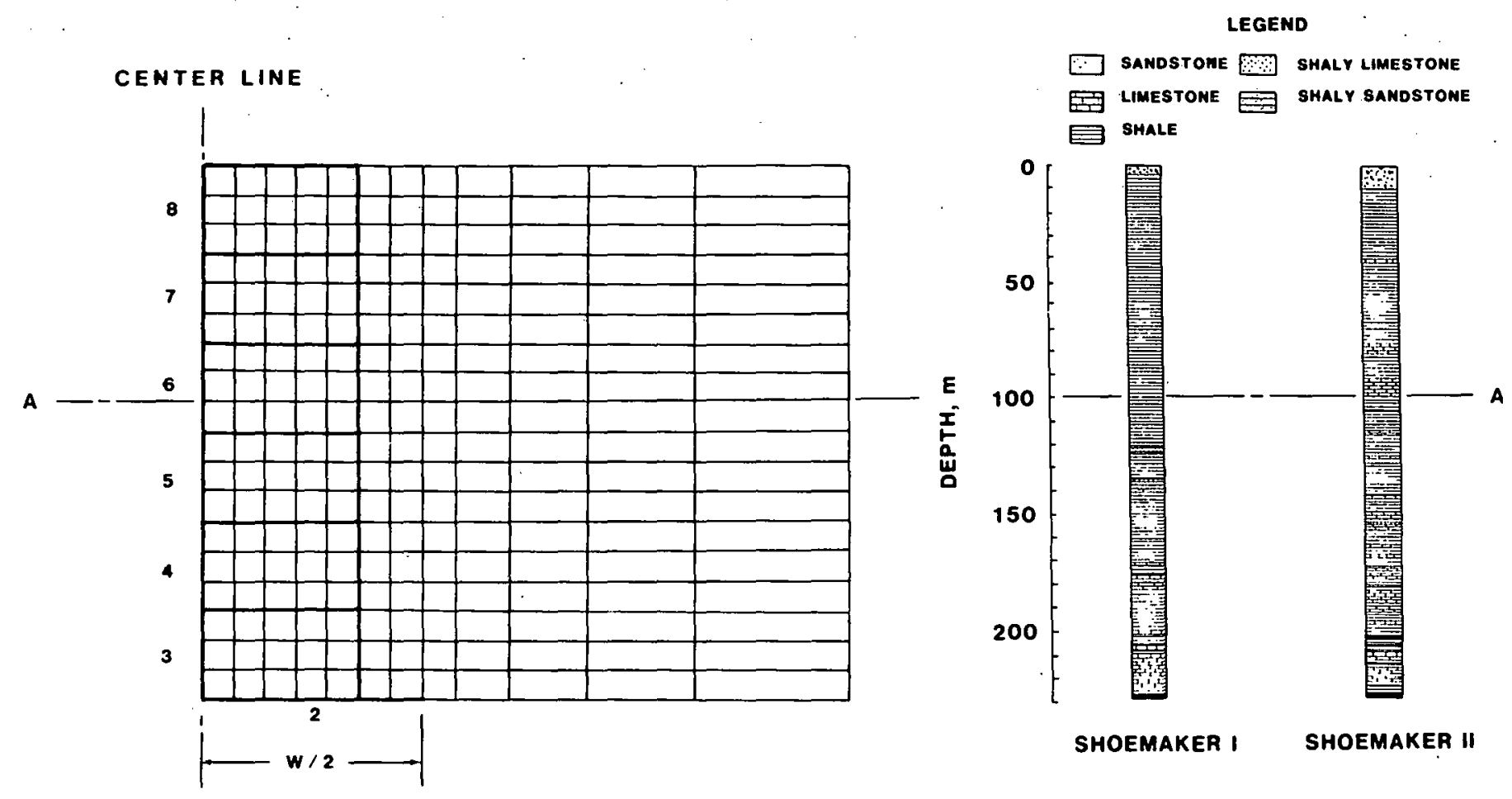

Figure 21. Finite Element Mesh used for Rubble Model Calculations and Stratigraphy Reported by Reference 4. The Heavy Lines Outline Failure Zones Numbered 3 Through 8. 
assumed that the entire overburden was a uniform block of homogeneous isotropic elastic material. In this calculation we reduced Young's Modulus of the rock mass to produce the observed maximum surface subsidence of $0.9 \mathrm{~m}$. As discussed earlier this technique of reducing elastic moduli, from those measured in the $l a b$ is a proposed technique to account for the presence of joints, bedding and other discontinuities in the rock mass. The resulting profile is shown in Figure 22 as the elastic prediction. Comparing this prediction to the observed profiles, the profile is spread out too far and its gentle curvature would significantly underpredict surface strains.

To the next degree of approximation, the stratigraphy between the mine level and the line $A A$ shown in Figure 21 contains much more limestone than. that lying above AA. This lower layer should be stiffer and more brittle than the overlying layer which, since it contains more shale, should be more compliant. The fact that this upper layer over the SII panel also contains some limestone beds suggests that failure would propagate further upwards in it than in the SI panel. However, when a two-layered elastic model is used in the calculations the subsidence trough is still too broad and gentle.

The non-elastic behavior which must be included to adequately describe the subsidence are the failure, bulking and compaction of the strata over the mine opening. As observed in the physical simulations performed on the centrifuge, the region above the panel fails and falls, and, in general is bmunded by a failure arch. For these preliminary calculations we have squared off this arch shape and considered a rectangular-shaped failure region. clearly the more limestone the strata contains the narrower the region should be relative to the panel width, because the stronger limestone layers will tend to corbel better and form an arch of narrower effective width.

For the SI panel, five elements in the coal seam were extracted to yield a total extracted width of $122 \mathrm{~m}$ and, as shown in Figure 21, failure was allowed in a zone five elements wide and ofdifferent heights denoted by levels 3 through 8. From the stratigraphy the failure would be expected to propagate 


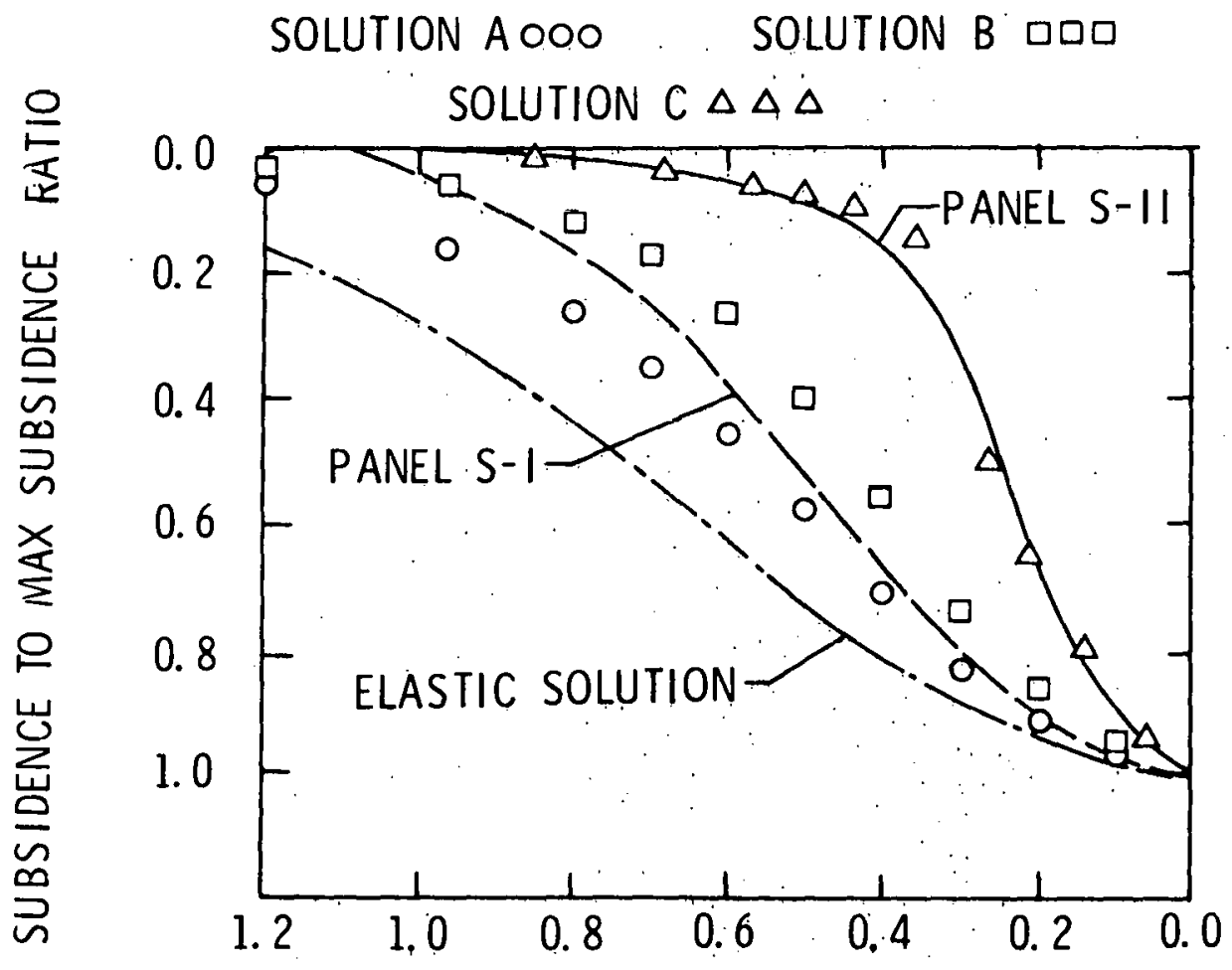

TRANSVEKSE DISTTANCE TO PANEL WIDTH RATIO

Figure 22. Comparison Between subsidence Observed over Shoemaker Mine Panels and Predictions of the Rubble Model 
up to the massive compliant shale layer and stop. The subsidence profile corresponding to this elevation (level 6) had a maximum subsidence of $0.74 \mathrm{~m}$ which is slightly less than the $0.91 \mathrm{~m}$ observed. As seen in Figure 22 this profile (labeled solution A) agrees closely with the observed SI profile over the panel; however as one proceeds away from the rib side; it lies below the observed profile. If one allows the failure to proceed further up into the strata to level 7 the maximum predicted subsidence is $1.05 \mathrm{~m}$ and the profile (labeled solution $B$ in Figure 22) always lies above the observed profile. Thus, this gross approximation to the fallure zone produces subsidence profiles which bound both the observed shape and the maximum surface subsidence. The calculation for the SII panel extracted seven elements in the coal seam for a total width of $177 \mathrm{~m}$. Because of the additional. limestone in the overlying strata, the effective failure zone width was taken to be five elements wide. Since this profile does not contain the thick shale layer near the surface, the failure levels might be expected to propagate higher up into the formation. The profile shown in Figure 22 (labeled solution C) corresponds to failure level 8 and is seen to clósely corréspond to the observed profile. The maximum surface subsidence for this profile was $1.17 \mathrm{~m}$ which is somewhat: greater than the $0.74 \mathrm{~m}$ observed.

Additional calculations have been performed with arched failure zones. These, as might be expected, yield profiles which more closely match those observed. However, we feel that more work needs to be done to adequately define the failure criteria to predict these zone shapes.

\section{SUMMARY}

The application of the European profile function techniques for describing the subsidence trough above longwall panels has been illustrated by examining the data from Old Ben No. 24 mine and the Shoemaker mine. In general, this and similar analyses indicate that the graphical methods typically used in the UK by the NCB are not good representations of the U.S. results. The best representation was found to be the profile functions of the type commonly used on 
the Continent. To date, no clear cut superiority has been established by either the trigonometric function or the error function.

There were observable features in the accurately measured development profiles which suggest time-dependent effects occur during and after the mining operation. These effects, while they do not diminish the value of the rate-independent empirical analysis through the profile functions, have considerable importance. The rate effects manifest themselves as nonantisymmetric displacements, late time trough deepening and an inability of the profile functions to accurately treat the subsidence behavior during mining stoppages. A correct simulation of subsidence must eventually incorporate such features.

A simple theory of subsidence is presented describing both the timedependent and time-independent aspects of the processes. The model examines both deformational modes and failure modes. Examination of the roof collapse process leads to the development of a void volume distribution function which described the bulking of fallen rock in terms of characteristic block dimensions.

Control of the bulking parameter through the void volume distribution function permits appreciable void volumes to propagate to the surface. Surface failures away from the excavation location can be interpreted as the angle of draw. Negative break angles are a natural consequence of the model. These key modes of material response have been implemented in numerical calculations and tested against both small scale physical models and full scale longwall panels. In the former, a relatively simple centrifuge model was used to demonstrate the complexities of geotechnical behavior and to present a challenging task for the numerical simulations. The particular model considered here is representative of a shallow mine drift in highly bedded stratigraphy. Progressive failure from the mine level up to the surface showed the formation of a stress arch in the unbroken strata and illustrated how the broken strata bulk, and eventually, offer support to the strata above. 
When failure had progressed to the surface a classic subsidence trough was observed. The analysis of this experimental data highlights the difficulty in predicting the failure sequence observed in the experiments. However, given the observed failure sequence, the post failure behavior of the rubble was adequately predicted using the Rubble model.

In the latter application, the same numerical techniques were applied to two longwall panels from the Shoemaker mine. These panels are unique because relatively minor variations in their stratigraphy produce significant differences in their subsidence troughs. Our analyses indicate that the massive block of shale that reaches from near the surface to $107 \mathrm{~m}$ below is the controlling feature. In panel SI this layer is essentially without partings, and acts as a "bridge" across the failed strata below. The formation of this thick, compliant, elastic beam creates a wide, gentle subsidence trough on the surface. In panel SII the shale layer has three major limestone partings. These brittle, stiff layers prevent a bridge from forming and the strata fail almost all the way to the surface. Thus, a narrow, steep subsidence trough is formed on the surface. 


\section{REFERENCES}

1. D. E. Munson and H. J. Sutherland, "Empirical and Analytic Approaches to Subsidence Prediction," Proceedings of the Polish-American Conference on Ground Control in Room-and-Pillar Mining, Y. P. Chugh, ed., August 1980, $11 \mathrm{p}$.

2. D. E. Munson and W. F. Eichfeld, "Evaluation of European Empirical Methods for Subsidence in U. S: Coal Fields," SAND80-0537, Sandia National Laboratories, Albuquerque, New Mexico, 1980.

3. D. E. Munson and W. F. Eichfeld, "European Empirical Methods Applied to Subsidence in U.S. Coal Fields," SAND80-1920; Sandia National Laboratories, Albuquerque, New Mexico, 1980.

4. V. Adamek and P. W. Jeran, "Evaluation of Existing Predictive Methods for Mine Subsidence in the U.S.," Proceedings of the lst Conference on Ground Control in Mining, S. S. Peng, ed., West Virginia University, July 1981, pp 209-219.

5. L. R. Powell, "Longwall Subsidence Case History Number 1, Northern Appalachian Coal Region," Open File Report, U.S. Bureau of Mines (in publication).

6. L. R. Powell, "Longwall Subsidence Case History Number 2, Northern Appalachian Coal Region," Technical Progress Report, U.S. Bureau of Mines, (in publication).

7. H. R. Handy, Jr., B. A. Anani, and A. W. Khair, "Microseismic Monitoring of a Longwall Coal Mine, Volume III, Field Study of Mine Subsidence," Final Report for Grant No. C0144013, Pennsylyania State University, Dept. of Mineral Engineering, October 1977, 139 p.

8. National Coal Board, Subsidence Engineer's Handbook (Hobart House, Grosvenor Square, London), 1975, $111 \mathrm{p}$.

9. G. Brauner, "Subsidence Due to Underground Minịng, Part 1," I. C. 8571, U.S. Bureau of Mines, Washington, DC, 1973.

10. A. Ajie and M. Hood, "Surface Subsidence Resulting from Underground Coal Mining," Mid-Year Report, Contract No. 62-0200, Dept. of Materials Science and Mineral Engineering, Univ. of California, Berkeley, March 1981,63 p.

11. S. Knothe, "Rate of Advance and Ground Deformation," Bergakademie, 5 , 513 (1953) (in German). S. Knothe, "Observations of Surface Movements and Their Theoretical Interpretation," Colliery, Eng. , 36, 24, 1958.

12. J. N. Edl, Jr., and W. F. Eichfeld, "Subsidence Related Data from Four Representative United States Coal Mines," S\& SE 78-2, Joint Research Project 14-01-0001-1451, Carbondale Mining Technology Center, DOE, 1978.

13. F. W. SChemchel, W. F. Eichfeld, and W. P. Santy, "Automated Data Acquisition for Subsidence Characterization," Proc. AIME Annual Meeting, New Orleans, LA, 1978.

14. R. A. Bauer, Illinois state Geological Survey, Urbana, IL (private communication). 
15. R. J. Orchard and W. S. Allen, "Time-Dependence in Mining Subsidence," Proc. Inter. Symp. On Minerals and the Environment, London, England, 1974, p 643 .

16. M. Hood, R. T. Ewy, L. R. Riddle, and J. J. K. Daeman, "Empirical Methods for Subsidence Prediction and Their Applicability to U.S. Mining Conditions," Final Report, Contract No.:62-0200, Dept. of Materials Science and Mineral Engineering, Univ, of California, Berkeley, October 1981, $241 \mathrm{p}$.

17. L. Obert and W. I. Duvail, 1967, Rock Mechanics and the Design and Structures in Rock, John Wiley \& Sons, NY, P 566.

18. D. E. Munson and S. E. Benzley, "Analytic Subsidence Model Using VoidVolume Distribution Functions," Proc. 2lst U.S. Symposium on Rock Mechanics, Rolla, Mo, May 27-30, 1980 .

19. P. B. Bucky and A. L. Fentress; "Applications of Principles and Similitude to Design of Mine Workings," Transactions of the American Institute of Mining and Metallurgical Engineers, 109 (1934), pp 25-50.

20. P. B. Bucky, "Use of Models for the Study of Mining Problems," American Institute of Mining and Metallurgical Engineers, Technical PUblication No. 425 (1931) pp 3-28.

21. H. J. Sutherland, R. A. Schmidt, K. W. Schuler, and S. E. Benzley, "Physical Simulations of. Subsidence by Centrifuge Techniques," Proceedings of the 20th.U.S. Symposium on Rock Mechanics, Society of Petroleum Engineers, Austin, Texas, 1979, pp 279-286.

22. H. J. Sutherland, K. W. Schuler, and S. E. Benzley, "Observations and Analytic Calculations of Strata Movement Above Idealized Mine Structures," Proceedings of the 7 th Annual Underground Coal Conversion Symposium, Fallen Leaf Lake, CA, September 1981, pp 221-233.

23. S. E. Benzley and R. D. Kreig, "A Continuum. Finite Element Approach for Rock Failure and Rubble Formation." SAND80-0227, Sandia National Laboratories, Albuquerque, NM, 1980, $24 \mathrm{p}$.

24. J. H. Biffle, "JAC - A Two-Dimensional Finite Element Code for the Nonlinear Quasi Static Response of Solids with the Conjugate Gradient Technique," SAND81-0998, Sandia National Laboratories,. Albuquerque, NM (in publication).

25. Z. T. Bieniawski, "Case Studies: Prediction of Rock Mass Behavior by the Geomechanics Classification," Proceedings 2nd Australia-New Zealand Conference on Geomechanics, Brisbane, Australia, 1975, pp 36-41.

26. F. H. Kulhawy, "Geomechanical Model for Rock Foundation Settlement," Journal of the Geotechnical Engineering Division ASCE, v 104, NGT2, February 1978, pp 211-227.

27. N. Barton, R. Lien, and J. Lunde, "Estimate of support Requirements for Underground Excavations," Design Methods in Rock Mechanics, C. Fairhurst and S. L. Crouch, eds., Am. Soc. Of Civil Engineers, New York, 1975, pp 163-177. 
M. Harthill

U. S. Dept. of Energy

Division of Coal Mining

Mail stop FE-25

Washington, DC 20545

A. Van Biesen

U. S. Dept. of Energy

Carbondale Mining Tech. Center

P. O. Box 2587

Carbondale, IL 26901

Phil Halleck

Los Alamos National Laboratories

Mail Stop 329 G-6

Los Alamos, NM 87545

Dept. of Materials Science and Materials Engineering

University of California

Berkeley, CA 94720

Attn: Prof. N.G.W. Cook M. Hood

Prof. S. H. Advandi

Dept of Engr. Mechanics

Ohio State University

Columbus, OH 43201

R. C. Speck

GAI Consultants, Inc.

570 Beatty Road

Pittsburgh, Monroeville, PA 15146

C. A. Goode

U. S. Dept. of Energy

Pittsburgh Mining Technology Center

P. n. Box 10910

Pittsburgh, PA 15236

U. S. Bureau of Mines

Division of Mining Research

2401 E Street NW

Washington, DC 20241

Attn: Chi-shing Wang

Rodger Bloomfield

Prof. Z. T. Bieniawski

Dept. of Mining Engineering

Pennsylvania State University

104 Mineral Science Bldg.

University Park, PA 16802

G. Harloff

Gulf $R \& D$

P. O. Drawer 2038

Pittsburgh, PA 15230
V. A. Scovazzo

D'Appolonia

100 Duff Road

Pittsburgh, PA 15235

Dept of Energy \& Nat. Resources Illinois State Geological Survey 1615 E. Peabody

Champaign, IL 61820

Attn: R. A. Bauer

P. DuMontelle

Peter J. Conroy

Dames \& Moore

1550 Northwest Highway

Park Ridge, IL 60068

U. S. Bureau of Mines

Twin Cities Research Center

5629 Minnehaha Ave. S

Minneapolis, MN 55412

Attn: L. Powell

S. Tandanand

U. S. Bureau of MInes

Spokane Mining Research Center

E. 315 Montgomery Avenue

Spokane, WA 99207

Attn: Paul McWilliams

Bill Stewart

Dan Kiley

T. W. Thompson

Dept. of Petroleum Eng.

University of Texas at Austin

Austin, TX 78712

Prof. S. Benzley

Dept. of Civil Engineering

Brigham Young University

Provo, Utah 84601

Prof. How-Kim Ko

Dept of Coal \& ENvironmental Engr. University of Colorado

Boulder, CO 80202

Dept. of Engineering \& Technology s. Illinois Univ at Edwardsville Edwardsville, IL 62026

Attn: R. S. Pocreva

R. Yarbrough

A. L. Stevens

Occidental Research Corp.

2100 SE Main $S t$.

Irvine, CA 92714 
DISTRIBUTION (Cont.)

R. $\dot{T}$. Weiss

Exxon Production Research Co.

P. O. Box 2189

Houston, TX 77001

J. E. O'Rourke

Woodward-clyde Consultants

Three Embarcadero Center, Suite 700

San Francisco, CA 94111

D. Wisecarver

U. S. Bureau of Mines

Denver Federal Center.

Denver, $\mathrm{CO}$

D. S. Choi

Conoco R\&D

P. O. Box 1267

Ponca City, OK 74603

J. Daemen

Dept of Mining \& Geological Engr.

University of Arizona

Mines 27

Tucson, AZ 85711

V. Adamek

U. S. Bureau of Mines

Pittsburgh Research Center

P. O. Box 18070

Pittsburgh, PA 15236

1500 W. A. Gardiner

1530 W. D. Caldes

1531 P. H. Adams

1531 R. L. Ault

1540 R. L. Brin

1543 E. H. Copeland

1543 C. G. Sain

$1545 \mathrm{~J} .0$. DAvis

4700 E. H. Beckner

4732 T. O. Hunter

4732 D. E. Munson

4747 P. J. Hommert

4748 B. E. Bader

4750 V. L. Dugan

4752 H. M. Dodd

4752 C: M. Goodrich

4752 R. L. MCNeill

4752 R. W. Prindle

4752 H. J. Sutherland (25)

4753 D. A. Northrop

4755 B. W. Marshall

4756 D. Engi

$4763 \mathrm{~J}$. Lipkin

4763. D. Tyler

4773 F. Ney

5500
5520

5521

5522

5522

5522

5523

5524

5530

5541

8214

31.41

3151

3154-3

T. B. Lane

R. D. Krieg

T. G. Priddy

R. P. Rechand

K. W. Schuler (25)

R. C. Reuter

L. W. Davison

W. Herrmann

Attn: B. M. Butcher, 5532

J. B. Rundle

M. A. Pound

L. J. Erickson (5)

W. L. Garner

C. Dalin

DOE/TIC (25 Unlimited Release) 


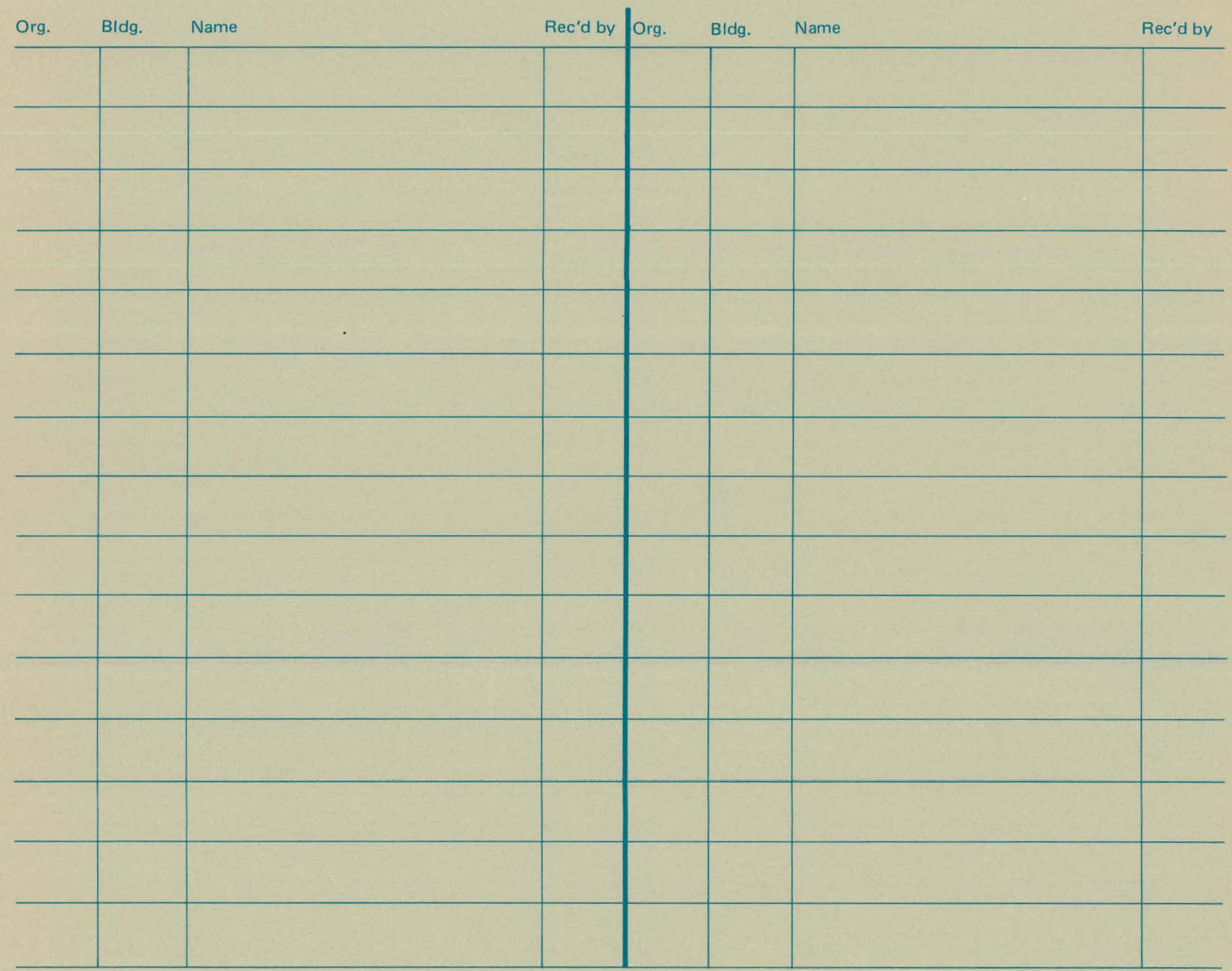

